\title{
Sobre Arqueología y Arquitectura en Medina Azahara. Entrevista a Rafael Manzano Martos
}

\section{On Archeology and Architecture in Medina Azahara. Interview with Rafael Manzano Martos}

\author{
Julia Manzano Pérez de Guzmán ${ }^{1}$, Pedro Barrero Ortega², Antonio Gámiz Gordo³ \\ Universidad de Sevilla
}

\begin{abstract}
RESUMEN
Rafael Manzano Martos, arquitecto y catedrático, dirigió Medina Azahara entre 1975 y 1985. La entrevista, ilustrada con fotos inéditas de su archivo privado, empieza recordando sus inicios en la arqueología y sus maestros Torres Balbás, Chueca Goitia, Gómez Moreno e Iñiguez Almech, con quienes se formó como restaurador de monumentos e historiador. Se comentan los criterios y el lenguaje de su importante intervención en el Salón Rico, tras hablar de su antecesor Félix Hernández y su contexto profesional. Se citan también sus intervenciones en el palacio de Yaafar, en la Dar al-Mulk, y en la Dar al-Yund. Se recuerdan sus inquietudes sobre la urbanística del conjunto, su jardinería, la traída de agua y electricidad, y la escasez de medios económicos o personales. Finalmente se comentan algunas singularidades de Medina Azahara, donde confluye su visión como arquitecto con la historia y la arqueología.
\end{abstract}

Palabras clave: Córdoba califal; Rafael Manzano; intervenciones; siglo XX.

\section{ABSTRACT}

Professor Rafael Manzano Martos, architect, was the director of the Madinat al-Zahra archeological site 19751985. The interview, ilustrated with unpublished photos from his private archives, starts by recalling his beginnings in archeology and his masters Torres Balbás, Chueca Goitia, Gómez Moreno and Íñiguez Almech, with whom he trained as restorer of monuments and historian. The criteria and language of his important intervention in the "Salón Rico" are discussed after talking about his predecessor Félix Hernández and his professional context. His interventions in the "palacio de Yaafar", in "Dar al-Mulk", and in "Dar al-Yund" are also mentioned. His concerns about urban planning, gardening, water and electricity, and the scarcity of economic resources and understaffing are recalled. Finally, some singularities of Madinat al-Zahra are discussed, where his vision as an architect converges with history and archeology.

Key words: Cordoba Caliphate; Rafael Manzano; interventions; $20^{\text {th }}$ century.

Recibido: 16-06-2017. Aceptado: 20-07-2017. Publicado online: 19-12-2017

Cómo citar este artículo / Citation

Manzano Pérez de Guzmán, J., Barrero Ortega, P. y Gámiz Gordo, A., 2017: "Sobre Arqueología y Arquitectura en Medina Azahara. Entrevista a Rafael Manzano Martos", Arqueología de la Arquitectura, 14: e064, doi: http://dx.doi.org/10.3989/arq.arqt.2017.021.

\section{Copyright}

(C) 2017 CSIC. Este es un artículo de acceso abierto distribuido bajo los términos de una licencia de uso y distribución Creative Commons Attribution (CC-by) España 3.0.

\footnotetext{
juliamanzano@gmail.com / ORCID iD: http://orcid.org/0000-0002-1656-0323 pedrojbarrero@yahoo.es / ORCID iD: http://orcid.org/0000-0002-0751-8713

antoniogg@us.es / ORCID iD: http://orcid.org/0000-0001-6188-3167
} 


\section{BREVES DATOS BIOGRÁFICOS}

Rafael Manzano Martos nació en Cádiz, el 6 de noviembre de 1936. Estudió en la Escuela Técnica Superior de Arquitectura de Madrid, donde se tituló en 1961. Fue discípulo escolar y extraescolar de los profesores Gómez Moreno, Torres Balbás, Íñiguez Almech, y Chueca Goitia, en cuyo estudio profesional colaboró durante toda su carrera y completó su formación profesional como arquitecto, restaurador de monumentos, e historiador del arte, de la arquitectura y del urbanismo. En esa etapa fue colaborador de la Escuela de Estudios Árabes (Instituto Asín Palacios del CSIC) donde cultivó su temprano interés por la historia y la arqueología islámica.

Al terminar su carrera, en 1961 se incorporó como arquitecto a la Dirección General de Bellas Artes, trabajando en la zona de Andalucía Occidental hasta 1982. También se incorporó al Servicio de Ordenación de Ciudades de Interés Artístico Nacional de la Dirección General de Arquitectura con trabajos en Galicia, Cataluña, Toledo, Toro, Alarcón, Valencia, Morella, y Andalucía, entre 1963 y 1970, cuando pidió excedencia para ocupar la Dirección del Alcázar de Sevilla.

Impartió docencia en la Escuela Superior de Arquitectura de Madrid, y desde 1966 en la Escuela Técnica Superior de Arquitectura de Sevilla, donde obtuvo por oposición la cátedra de Historia de la Arquitectura y del Urbanismo - Teoría y Técnica de la Restauración de Monumentos. Allí ha impartido su docencia durante cerca de 40 años, siendo sucesivamente Secretario, Subdirector-Jefe de estudios, y finalmente Director-Decano entre 1974 y 1978.

Desde 1970 a 1988 fue Director-Conservador-A1caide de los Reales Alcázares de Sevilla, tras la muerte de Joaquín Romero Murube, bajo cuya dirección ya venía realizando obras de restauración en los mismos. Allí excavó el palacio islámico ubicado en el solar en el que luego se asentaría la Casa de la Contratación de las Indias. También encontró los restos de una basílica paleocristiana en el patio de Banderas del Alcázar, intervino en el mirador medieval del palacio del Rey Don Pedro, y acometió otras diversas restauraciones en los patios del Asistente, de Levíes, del Crucero, del Sol, del Alcaide, del Yeso, de las Doncellas, etc.

En el ámbito arqueológico cabe destacar sus trabajos en la ciudad califal de Medina Azahara en Córdoba, de la que fue Director-Conservador entre 1975 y 1985. Intervino en sus más importantes áreas: en el Salón Rico, donde continuó la labor iniciada por D. Félix
Hernández; en la antigua Dar al Yund, o palacio militar de planta basilical, que pretendía cubrir para organizar un pequeño museo; en el Salón Occidental o Dar alMulk, que había excavado D. Ricardo Velázquez Bosco; en el palacio de Yaafar, en su inmediato patio y jardín de la Alberquilla; y en los grandes arcos de la al-Muzara o Plaza de Armas.

En abril de 2016 Rafael Manzano Martos fue condecorado con la Medalla de Honor de las Academias de Andalucía.

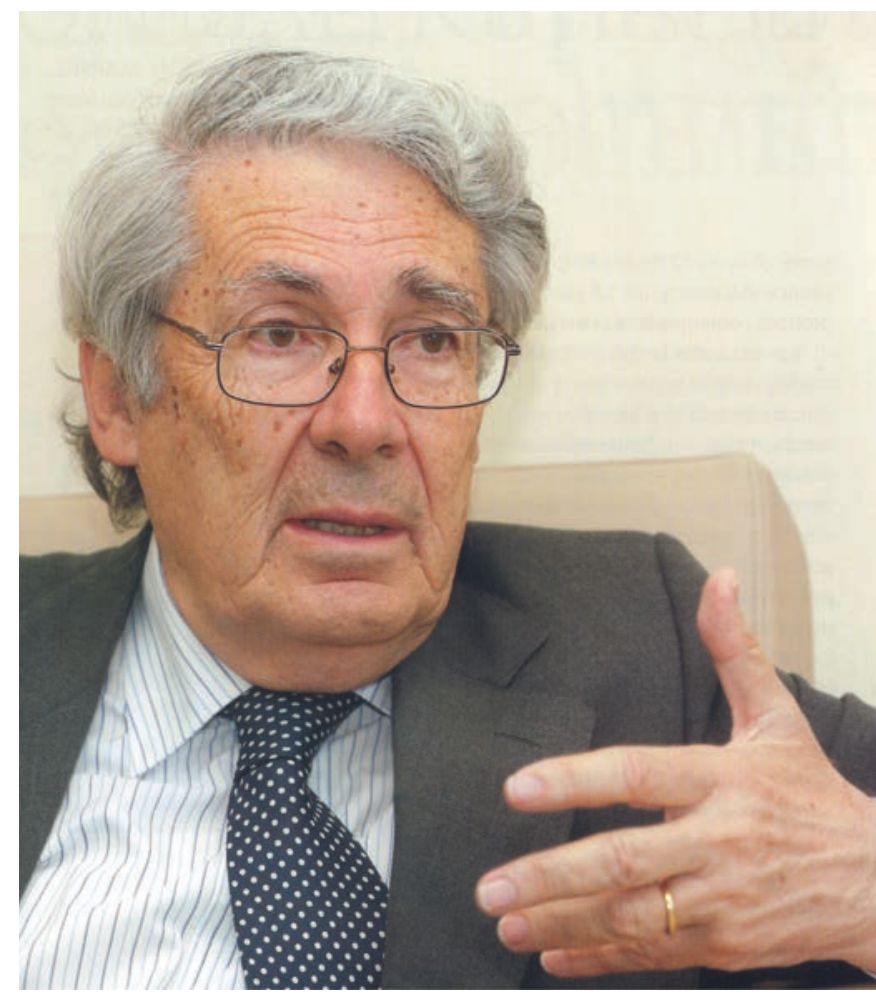

Fig. 1. D. Rafael Manzano Martos (foto Alberto Carrasco).

\section{ENTREVISTA REALIZADA EL 31 DE MARZO DE 2016 (REVISADA EN 2017)}

\section{¿Recuerda cómo se inició su interés por la arqueo- logía?}

Mis inicios en la arqueología fueron muy tempranos y precoces. Fui muy amigo en Jerez de quien considero mi primer maestro, D. Manuel Esteve Guerrero, un gran arqueólogo e historiador del arte que hizo la primera guía conocida de Jerez, cuando todo el mundo venía a la ciudad tan solo a visitar sus bodegas, y a nadie se le ocurría ver las obras magistrales de arquitectura o su prodigiosa colección de iglesias y conventos. 
Él excavaba en Jerez un yacimiento antiguo y medieval en el que pensaba que podía estar el solar de la antigua Tartessos. Eran las ruinas de Asta Regia, que se han tenido por origen de Jerez, aunque yo no creo que la ciudad tuviera allí su origen, ni que ésta fuese la capital de Tartessos, pero desde luego fue una ciudad tartésica, cuya cerámica él exploró y delimitó como específica de aquella cultura. Yo le acompañé y le ayudé a levantar planos. Mis primeros conocimientos de la técnica arqueológica se deben a su magisterio.

\section{¿Le hablaron como estudiante sobre las relaciones entre arquitectura y arqueología?}

No, porque yo estudié en una Escuela de Arquitectura en la que entonces se odiaba la arqueología, la arquitectura del pasado y todo lo que significara historia, como ya la odió la Bauhaus. Todos se sentían muy fieles a la anti-historia, porque como Walter Gropius creía, pensaban que la historia de la arquitectura había hecho mucho daño al arquitecto y lo había ido rezagando por el camino de la copia, de la tradición y del clasicismo, del cual había que huir y renegar profundamente. Esa era en aquel tiempo la actitud en la Escuela de Arquitectura de Madrid y de su hermana la de Barcelona.

\section{¿Con qué maestros se formó en el mundo de la ar- queología?}

D. Leopoldo Torres Balbás fue sin duda mi maestro. Fue un magnífico profesor formado en la Institución Libre de Enseñanza, y además el gran restaurador de la Alhambra de Granada. Admirábamos su prestigio y le queríamos porque era un hombre profundamente liberal, y era un pedagogo magnífico.

Mantuve con él una amistad y una convivencia fantástica. Recuerdo que le acompañé en un viaje hasta Alcalá la Vieja, aunque en realidad la más vieja fue la antigua Complutum, que primero estuvo en el cerro del Viso, luego se trasladó a la llamada Qalat abd el Salam (Alcalá la vieja), y después volvió a trasladarse al otro lado del río, al solar de la actual Alcalá de Henares. En aquella visita tuvimos que vadear el Henares, porque él pensaba, según unas cartillas de la Sociedad Española de Excursiones, que había una barca para cruzar, pero ya no existía, tan solo quedaba el palo a donde se amarraba en la orilla. De Qalat abd al-Salam levantamos planos, la estudiamos y él la publicó entre las ciudades yermas de la España Musulmana, en un magnífico artículo en el Boletín de la Real Academia de la Historia.

Con Fernando Chueca actué en algunos monumentos medievales cuando era estudiante, y al terminar la carrera me estaban esperando tanto la Dirección General de Bellas Artes como la de Arquitectura para darme trabajo. Hoy lastimosamente las cosas no son así para los jóvenes. Yo era el único arquitecto de la Escuela de Arquitectura que, desde los años anteriores a la guerra, se había venido preparando durante la carrera para la restauración de monumentos. Ninguno de mis compañeros, ni de cursos anteriores al mío, ni de los inmediatamente posteriores, se había ocupado de ello. Yo había trabajado con D. Leopoldo Torres Balbás, después con D. Fernando Chueca Goitia y con D. Manuel Gómez Moreno, y estábamos preparando un libro de la historia de la arquitectura española antigua y medieval. En España, que aún estaba en la postguerra, había mucho que hacer en materia de restauración de monumentos.

\section{¿Cómo fueron sus inicios profesionales en relación con la arqueología?}

Según he comentado tuve trabajo el mismo día en que terminé la carrera. Me llamaron de la Dirección General de Bellas Artes para que prestase allí mis servicios, y enseguida me confiaron trabajos en los que tuve que hacer evidentemente alguna labor de carácter arqueológico.

Siempre que se actúa sobre un monumento se está tocando su arqueología. El historiador o el restaurador de la arquitectura utiliza conocimientos arqueológicos de diversas épocas, prehistórica, romana, visigótica, medieval, e incluso yo diría que hay arqueología de época moderna e industrial. El monumento siempre obliga a estudiar su estado inicial, su pasado y su presente, y eso en el fondo tiene una sistemática afrontada por la arqueología, como forma de documentar y fechar lo que se está restaurando.

Por tanto, el historiador del arte y el restaurador de monumentos están siempre con la arqueología en la mano y al servicio de esa arqueología; así como la arqueología está al servicio del arquitecto para documentarlo y capacitarlo, para tocar lo que es muy delicado, pues todo monumento tiene su pasado.

Se puede decir que yo nunca he actuado como arqueólogo, he actuado como arquitecto al servicio de la arqueología, que es distinto. Así, en casi todas mis actuaciones en Medina Azahara, lo que hice fue ordenar, recolocar, organizar y reestructurar los restos heredados de excavaciones anteriores. 


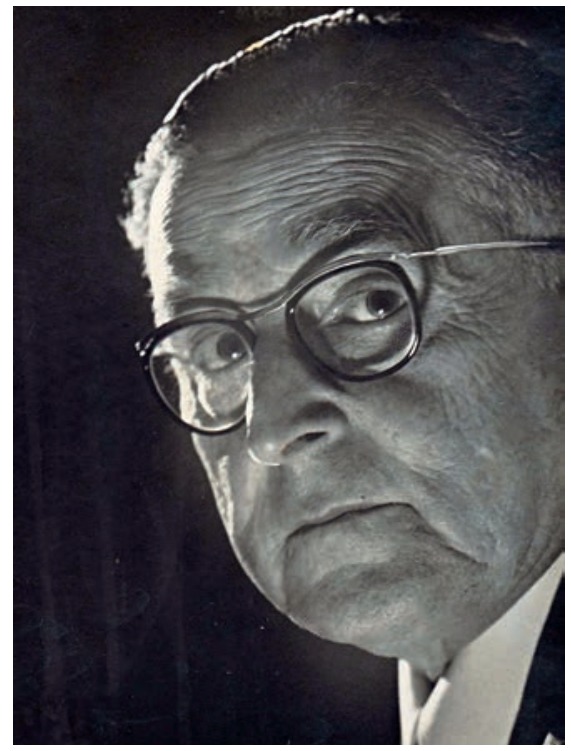

Fig. 2. D. Manuel Esteve Guerrero (Archivo privado Rafael Esteve González).

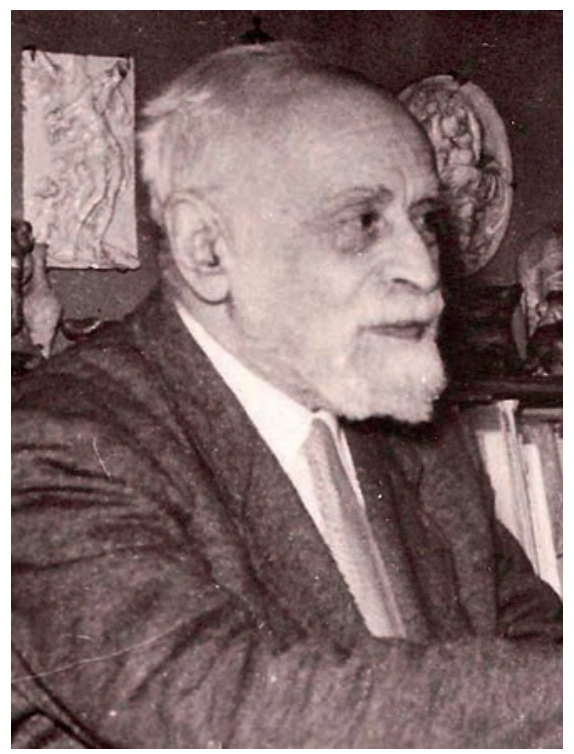

Fig. 5. D. Manuel Gómez Moreno (ARM).

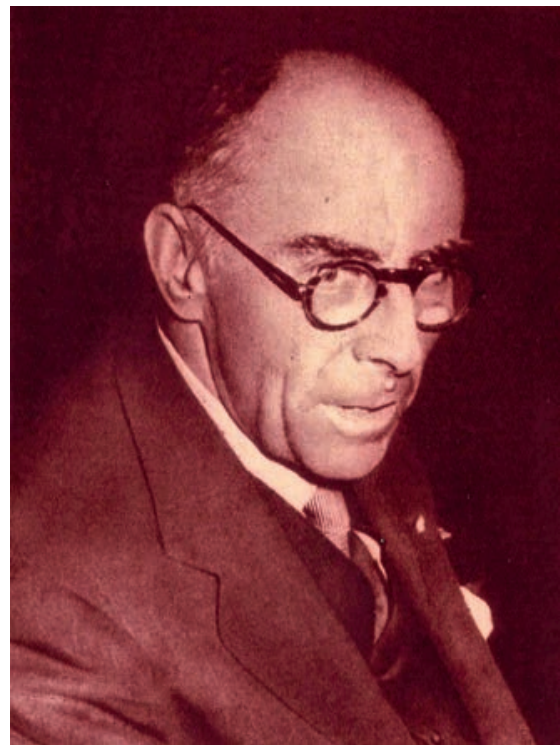

Fig. 3. D. Leopoldo Torres Balbás (Archivo privado R. Manzano).

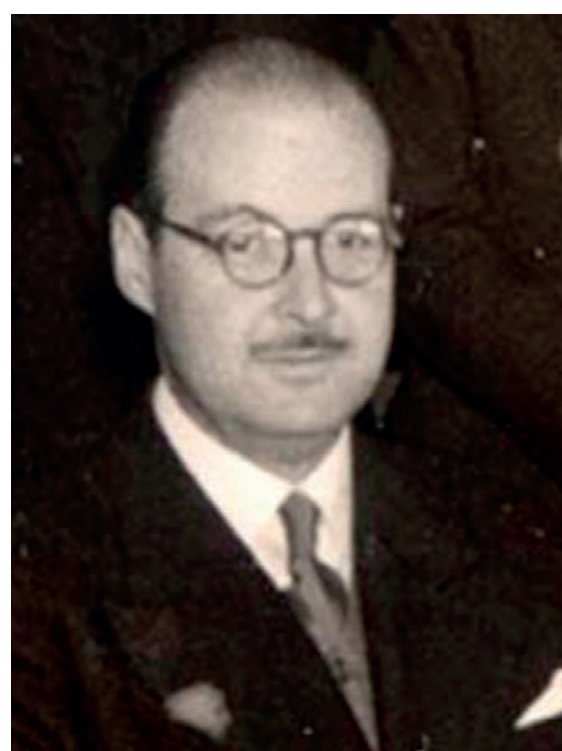

Fig. 6. D. Francisco Íñiguez Almech (ARM).

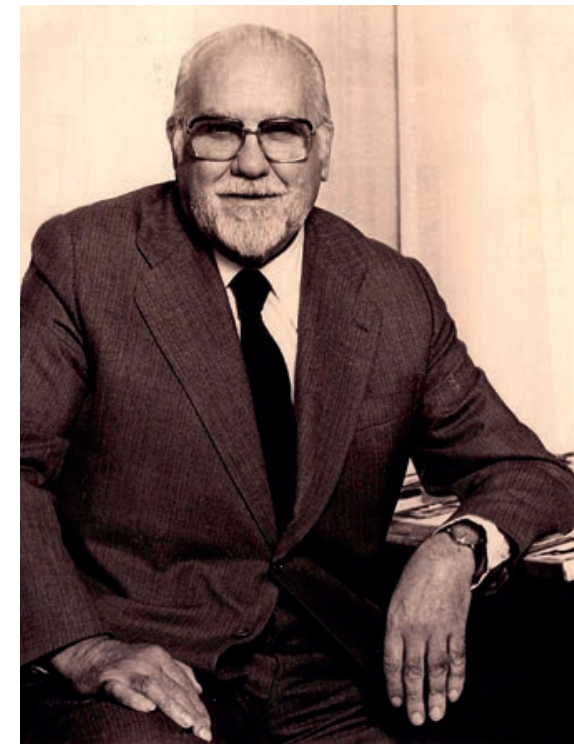

Fig. 4. D. Fernando Chueca Goitia (ARM).

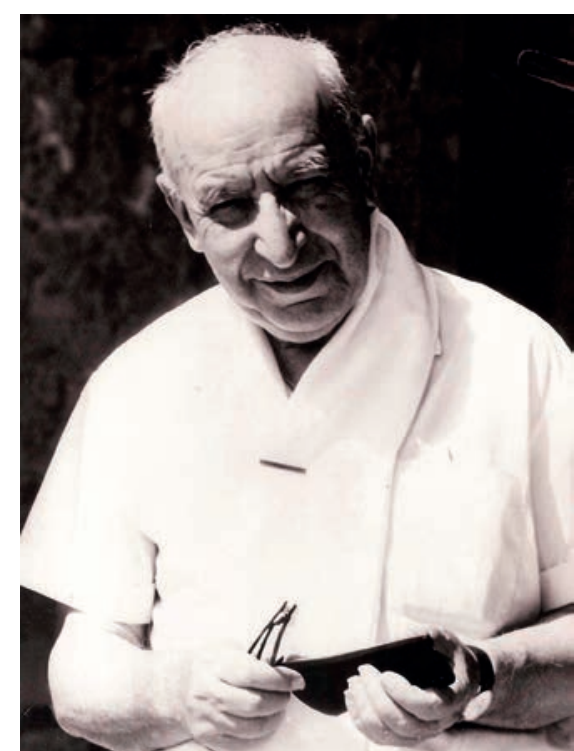

Fig. 7. D. Félix Hernández Giménez (ARM).
En mis inicios profesionales mantuve mucho contacto con D. Fernando Chueca, que era más arquitecto que arqueólogo, y aún más historiador de la arquitectura que restaurador de monumentos. Con él acometí intervenciones modestas, dotadas de muy escaso presupuesto. Trabajé como colaborador suyo al servicio de la Dirección General de Bellas Artes en la zona de Aragón, de Navarra, del País Vasco, con actuaciones anuales que consistían en arreglar las partes más en riesgo de ruina de monumentos afectados, nunca se llegaba a una restauración integral. Casi siempre el dinero se acababa antes de terminar el año y había que esperar hasta la actuación del año siguiente, que dependía de la dotación que la Dirección General de Bellas Artes pudiese asignar.

También trabajé al lado de D. Francisco Íñiguez y seguí sus trabajos en la Aljafería de Zaragoza, donde aprendí de arquitectura islámica, en la que yo estaba muy interesado, y en la cual D. Leopoldo era una autoridad. El propio Chueca también sabía mucho de arquitectura hispanomusulmana aunque no fuera un arqueólogo especializado en ese tema; pero en el Manifiesto de la Alhambra dejó escrita una teoría muy poética de su valor frente a la arquitectura del futuro. Trabajé mucho con 
todos ellos, sobre todo con D. Manuel Gómez Moreno, que a pesar de su afición y talento para el estudio de la arquitectura, era un arqueólogo puro, hijo de un gran arqueólogo, además de pintor, que estuvo pensionado en Roma, y por ello en su juventud se imbuyó allí de clasicismo y de fervor por la arquitectura y la arqueología.

Seguramente su actividad en Medina Azahara ha sido una de las más importantes en su carrera profesional. ¿Cuáles son sus primeros recuerdos de este lugar?

Efectivamente una de las actividades que más me han marcado personalmente ha sido mi trabajo en Medina Azahara. Mantengo una importante nostalgia de ello, aunque recientemente he vuelto a trabajar allí, según comentaré después.

Visité Medina Azahara muy joven, cuando D. Félix Hernández era director del monumento, allá por los años cincuenta, incluso antes de ser estudiante de arquitectura. También hice una visita cuando estaba terminando la carrera, en un viaje de una semana por Andalucía dirigido por D. Francisco Íñiguez. Como yo conocía muy bien todos los monumentos, el propio Íñiguez me pidió que los explicase, y tuve la satisfacción de hacerlo a mis compañeros. Lo pasamos muy bien, fue un viaje fantástico y D. Félix nos acompañó a Medina Azahara, donde ofreció primorosas explicaciones conmigo. Era un gran arqueólogo, más arqueólogo que arquitecto. Luego, cuando empecé a dar clase en la Escuela de Arquitectura de Madrid, el primer año vinimos al sur, y también llevé a los alumnos a Medina Azahara.

Poco después me llamó el entonces Director General de Bellas Artes, Gratiniano Nieto, y me dijo que debía irme a Andalucía, a Córdoba, donde me darían algún trabajo, y me pidieron que hablase con D. Félix y con el alcalde de Córdoba. Querían que ayudase a D. Félix, que era muy mayor, pues pensaban que, tras su jubilación, haría falta alguien que conociera a fondo el monumento para seguir actuando sobre él.

Visité al alcalde de Córdoba y me dijo que tenían un gran problema con muchas casas cordobesas, más o menos monumentales, que querían derribar y que la gran incomprensión entre los arquitectos de la Dirección General de Bellas Artes y los arquitectos cordobeses, lo impedían. Pensaba que estando yo allí, que era joven y moderno, haría de puente entre ambos, pero le dije que yo no venía a tirar casas, sino más bien a todo lo contrario, a intentar conservar el conjunto monumental.
Aunque no fue posible, me hubiese encantado trabajar al servicio del ayuntamiento de Córdoba y de la Dirección General de Bellas Artes.

En los días siguientes D. Félix me dijo que estaba muy enfadado con el Director General, Gratiniano Nieto, porque sabía que le querían nombrar un sustituto, un sucesor o un auxiliar con derecho a sucesión. Además estaba indignado porque le habían mandado a un arqueólogo como espía y se sentía molesto porque le inspeccionasen su trabajo. Y concluyó, "quiero que usted me ayude, pero desde Sevilla, no en Córdoba donde ya estoy yo". Nunca quise complicar la vida a una persona a la que admiraba y quería mucho.

Acabé en Sevilla por otros motivos, y tuve una gran relación con D. Félix, aquí nos veíamos, comíamos juntos, íbamos a Itálica... Sin embargo él siempre hablaba "in ocultis", quizás por su compleja dicción, o porque no quería que se conociese lo que pensaba de Medina Azahara. Yo redescubrí Medina Azahara por mi cuenta y razón, después de las largas conversaciones con D. Félix, sin apoyarme en lo que le había oído, ni en lo escrito en su publicación sobre Medina Azahara editada por la Alhambra en sus últimos años, que no es demasiado inteligible. Dicho libro me recuerda a la "Carpintería de lo Blanco" de Diego López de Arenas, que decía que no quería hablar claro, no fuera que los oficiales se convirtiesen en maestros y los aprendices en oficiales, pues pensaba que la formación debía producirse lentamente y no leyendo un libro que supuestamente provocase una rápida conversión en maestro. Así pues, D. Félix no quería que le arrebatasen los secretos del monumento, pero yo le estimaba mucho, era un ser adorable y valiosísimo. Recuerdo que me preguntaba cosas y luego casi siempre hacía lo contrario de lo que le aconsejaba. Pero venía a pedirme consejo, y eso ya era algo en él.

\section{¿En qué obras de Sevilla trabajaba por entonces?}

Realizaba trabajos de tipo arqueológico en la puerta de Córdoba que estaba restaurando D. Félix y yo terminé, al igual que concluí la restauración de la iglesia de San Hermenegildo, con la nueva fachada lateral hacia la que fue comisaría de policía. También hacía obras en la iglesia de la Merced de Osuna, que se había hundido y reconstruí la cúpula, y en la interesante iglesia góticomudéjar de Santiago de Écija, etc.

En Itálica acometía trabajos de pura y estricta consolidación arqueológica, especialmente en el anfiteatro, despejando los barros acumulados de su fachada trasera. Por un problema muy grave hubo que hacer un drenaje perimetral, ya que la colina drenaba en la zona norte del 
anfiteatro, y los sedimentos y arcillas lo habían ido cegando progresivamente. Además hice un estudio para ordenar la manzana de la Casa de la Exedra, que había analizado muy bien García Bellido, y también para consolidar el patio con su impluvium y sus curiosas formas curvilíneas.

Todo ello tuvo lugar bajo la vigilancia de un arqueólogo jefe, D. Juan de Mata Carriazo, con el que me entendía muy bien porque me conoció en una tertulia vespertina en casa de D. Manuel Gómez Moreno, muy venerado por él, y por ello gocé de su protección y afecto en Sevilla.

\section{¿Cómo fue su llegada al conjunto arqueológico de Medina Azahara y cuáles fueron sus más destacadas intervenciones?}

En los últimos días de vida de D. Félix, cuando estaba muy enfermo me llamó su hija y fui a verle. Recuerdo que me dijo las siguientes palabras: "cuando yo muera le llamaran para que se ocupe de esto, y si se lo piden no tenga usted escrúpulos, acepte, porque es quien mejor puede hacerlo, y procure que nadie olvide que Medina Azahara no es trabajo de arqueólogos, sino de arquitectos".

Tras la muerte de D. Félix, recibí un oficio de la Dirección General de Bellas Artes, del Arquitecto Jefe de Monumentos y Conjuntos, para que me hiciese cargo de la dirección del conjunto arqueológico de Medina Azahara. Planteé un programa de actuaciones que, entre otras cosas, quería agilizar lo que D. Félix venía haciendo. Él era muy lento y dudaba mucho. Recuerdo que en San Hermenegildo hizo una maqueta en escayola de la buhardilla y cada día el escayolista tenía que modificarla, bajarla o subirla unos milímetros, y el tiempo se nos iba en contemplarla hasta llegar a la solución final. Era tremendo, minuciosísimo.

Desde el principio tuve que sistematizar mi trabajo, ya que no podía ir todas las semanas a Medina Azahara, por mi dedicación a la cátedra y al Alcázar de Sevilla. Iba incluso sábados y domingos, con mi mujer y mi hija, y en verano pasaba allí semanas. Empezábamos a trabajar con los primeros rayos del sol, hasta las tres de la tarde, cuando el calor ya no se podía soportar.

Mi intervención más importante tuvo lugar en el Salón Rico, que es una pieza esencial de Medina Azahara. Inicié una táctica de ordenación del material de ataurique ya excavado. En este lugar no excavé absolutamente nada, pues aquel espacio ya era un campo de restos arqueológicos más o menos excavados por zonas. Le hice ver al ayudante o montador que tenía allí, que se llamaba Salvador, que en cada paño había actuado un maestro diferente, aunque los conceptos o motivos eran los mismos, generalmente árboles de la vida. Pero los detalles eran distintos, y por ejemplo había unos tallos curvos, otros planos, otros con triangulitos o con rayitas... Yo le pedía que se agrupasen todas las piezas con detalles similares, para después proceder a su reintegración. Se especializó en aquello y resultó realmente impresionante lo bueno que era acoplando fragmentos. La verdad es que al acercar dos piezas que habían sido una, sus bordes se atraían como imanes, y ello nos permitió avanzar muchísimo en la reintegración del Salón Rico. Además, aunque no había una simetría especular, existían unas leyes de lazo, y cuando un tallo se cruzaba con otro, pasaba por debajo o por encima alternativamente, y si tenías un lado, por simetría, se conocía el dibujo completo.

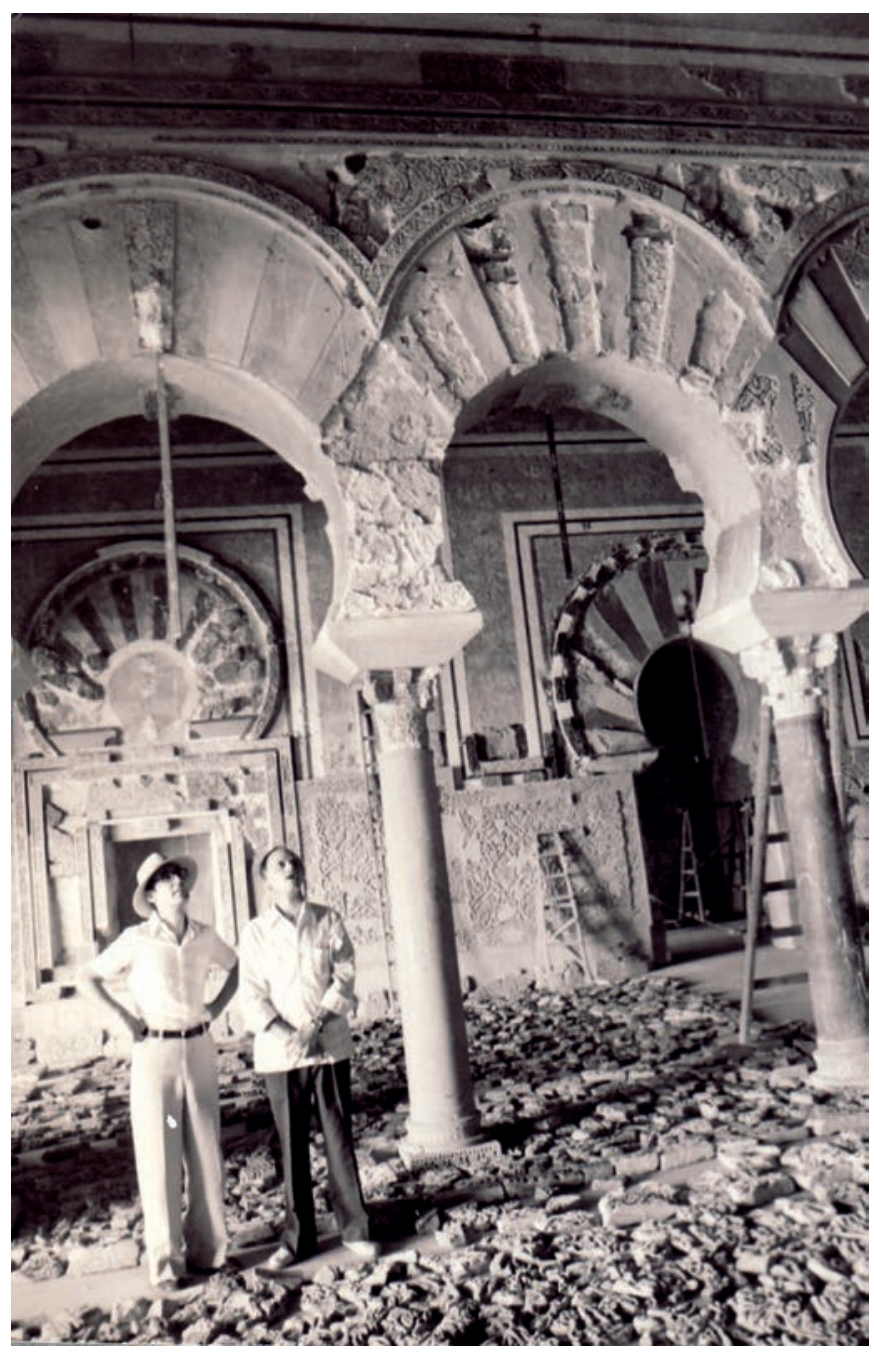

Fig. 8. Rafael Manzano en pleno montaje de los restos del Salón Rico de Medina Azahara, con un visitante no identificado (ARM). 
Resultaron muy importantes las muestras que D. Félix ya había hecho para dar un acabado final a las áreas donde no había piezas auténticas. No debe olvidarse que Medina Azahara mantiene su autenticidad material en un porcentaje muy alto, y había paneles en los que faltaban muy pocas piezas, casi todo era auténtico. Yo mismo hice distintas pruebas, que aún se conservan allí y que son un testimonio de mi preocupación por encontrar un lenguaje adecuado para integrar, al par que
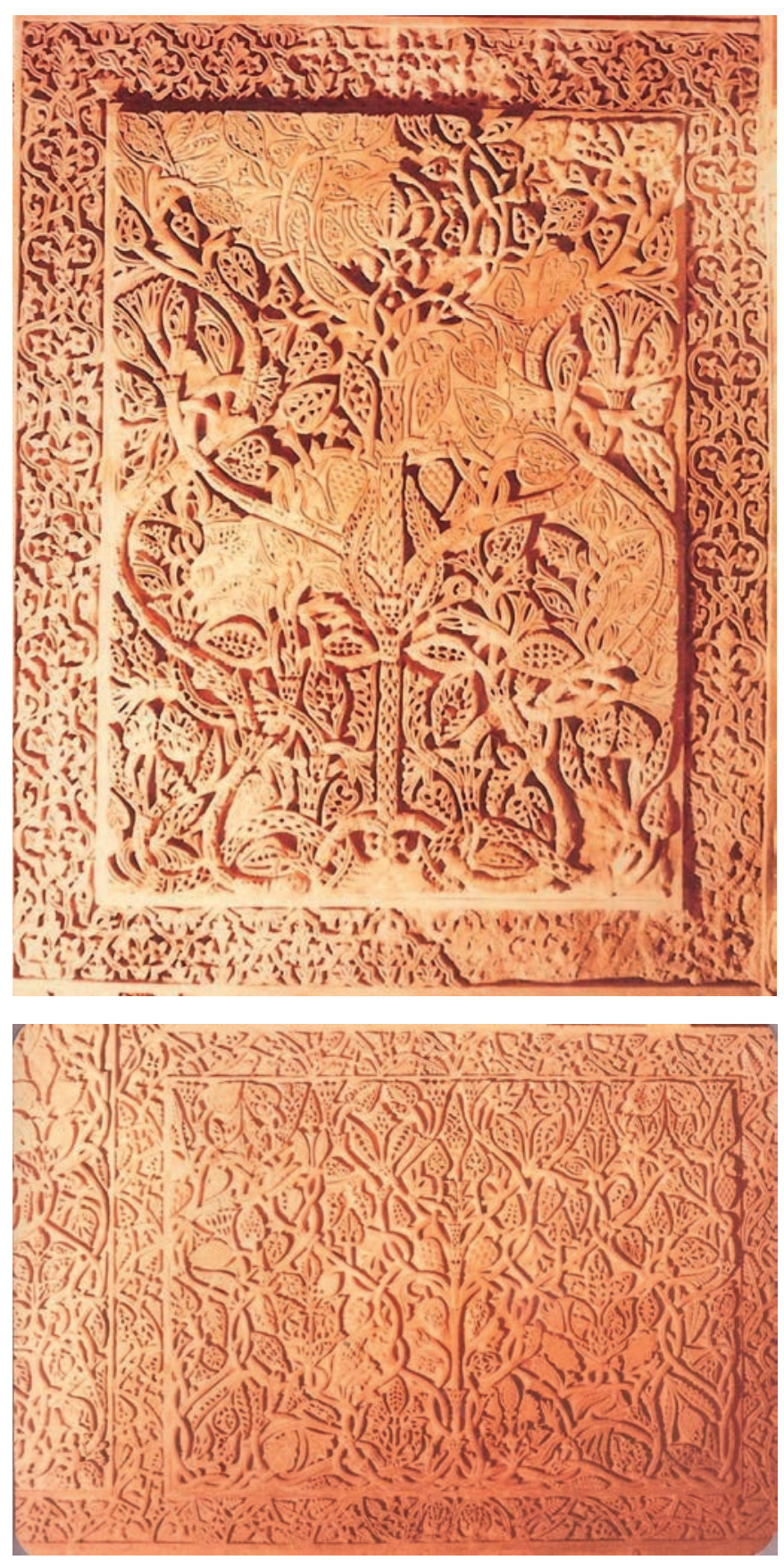

Fig. 9. Paños de ataurique con fragmentos reintegrados en el Salón Rico (ARM). diferenciar, lo original y lo nuevo. Hubo un momento en que creí haberlo encontrado y me pareció más bella la solución que la realizada por mi antecesor, distinguiéndose perfectamente lo añadido de lo auténtico. Cuando había garantía se reponía con otro material, yeso en vez de piedra, el elemento que faltaba, en su silueta o dibujo básico, con un relieve mínimo. Por supuesto, los elementos singulares se dejaban en liso, y en algunos se dibujaba la piedra que le servía de base. Incluso en fotografías se percibe perfectamente lo que es auténtico y lo que no lo es.

Al tener claros dichos principios se pudo reponer el lado izquierdo del Salón Rico casi en su totalidad. Así, en una década se produjo allí un cambio de apariencia sustancial, entre otras cosas porque coloqué las piezas que inundaban los suelos, todo el material antiguo disponible, evitando que se perdiesen algunas de estas piezas, como antes ocurría.

Otra intervención importante tuvo lugar en la cubierta del Salón Rico que protegía las citadas piezas

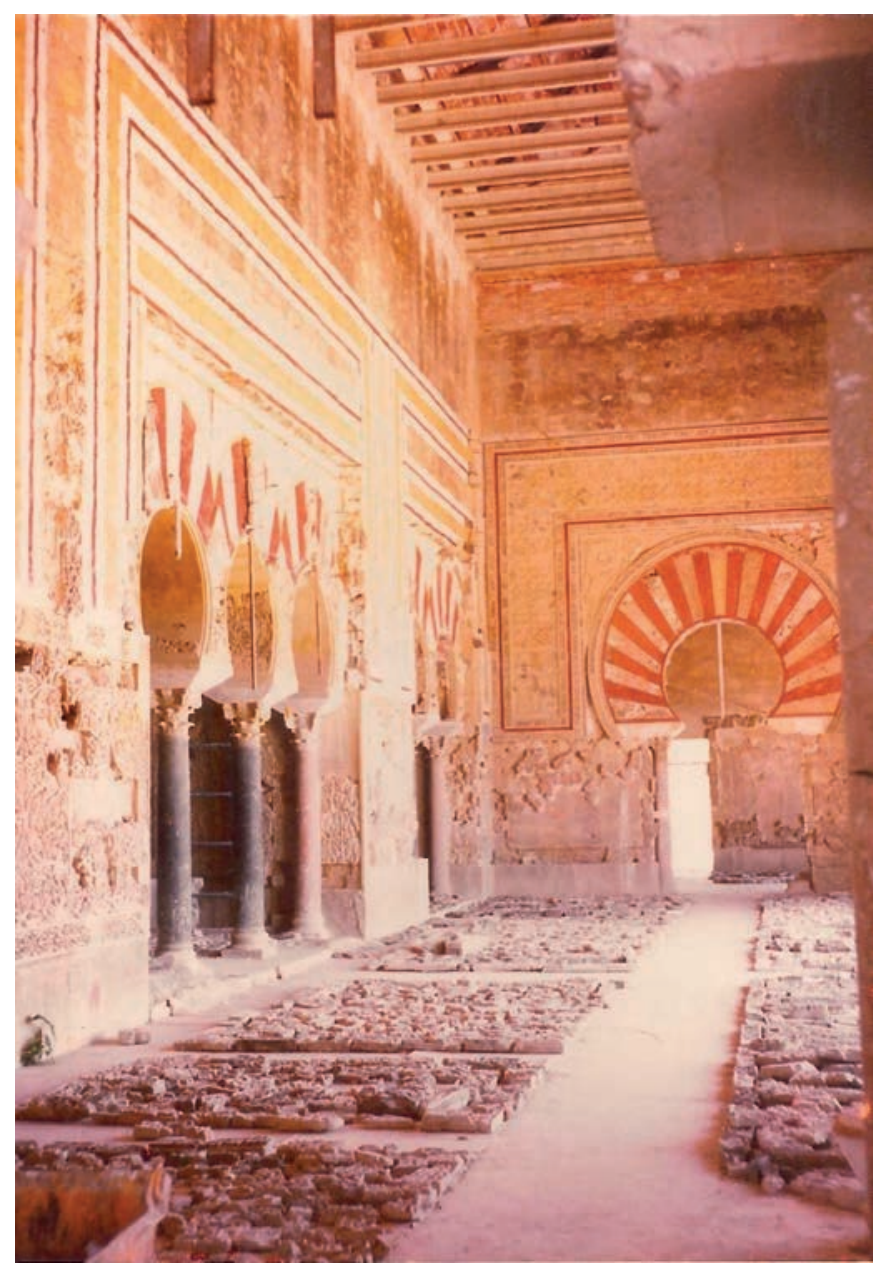

Fig. 10. Fragmentos ordenados en el Salón Rico (ARM). 
excavadas. Ya estaba cubierto, pero de forma muy primaria, pues D. Félix era muy economicista en sus obras y había usado piezas desechadas por una fábrica de viguetas de cemento, algunas muy deformes, que hubo que sustituir por otras de más calidad. Estaban forradas de yeso y con la humedad del propio monumento y las condensaciones de las cubiertas, empezaron a caer los trozos del revestimiento sobre los turistas, y por ello se adoptó una solución más definitiva, más depurada, con falsas vigas de madera. No llegué a cubrir la nave de la derecha y los tableros se quedaron allí sin colocarse, y se han utilizado para mil cosas, incluso para hacer leña, pero no se han colocado. En esa zona permanece el techo de yeso de D. Félix, generando cierta confusión, pues parece que una solución es antigua y la otra moderna. El lenguaje de la restauración debería ser lo más unitario posible para evitar confusiones.

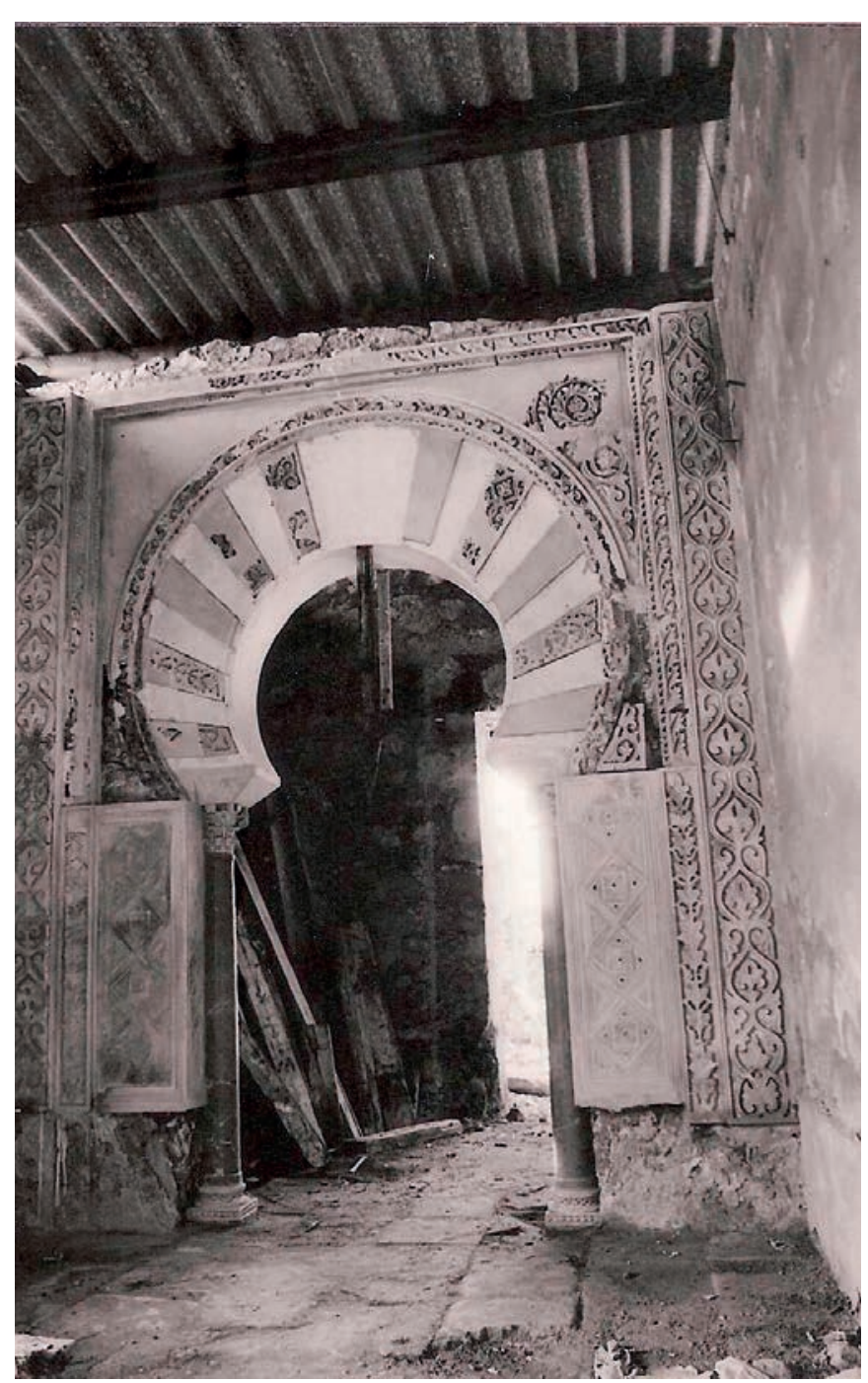

Fig. 11. Techo del Salón Rico durante las intervenciones (ARM).

\section{¿Qué otras intervenciones acometió o pensaba aco- meter?}

Me preocupó todo lo que podía montarse con cierta facilidad, como por ejemplo las portadas de determinados edificios y las galerías de los patios. Consolidé la excavación de la Dar al Visir, el palacio de Yaafar y la casa aneja a este edificio.

La única excavación que acometí en Medina Azahara fue en la Dar al Mulk, la casa de los Califas, en la parte más alta. Allí se encontraba, ya semiexcavada, una de las dos torres de escalera que enmarcaban su terraza. Quería comprobar si había otra simétrica, y efectivamente la había. En realidad no entré en estratos inferiores, solo limpié hasta el arranque de los peldaños, felizmente existentes, de la escalera primitiva, que conectaba el plano bajo de la ciudad con la Dar al Mulk.

También me ocupé de la decoración excavada en el año 1918 por D. Ricardo Velázquez Bosco, en aquel mismo edificio, que se estaba perdiendo y que pude llegar a ordenar para su montaje, de la que solo tuve tiempo para montar una arquería. Pensaba levantar la fachada de la Dar al Mulk, como importante hito visual que corona Medina Azahara. Era un palacio con tres portadas yuxtapuestas. Hubiera sido fantástico verlas en la parte alta del conjunto. Allí estaban todas las piedras. A Velázquez Bosco le sorprendía que fueran tan reiteradas, pues las tres puertas eran más o menos idénticas.

Además me ilusionaba otra importante intervención en la Dar al Yund, la casa del ejército, que era el más grande de los palacios y el único desornamentado por su carácter militar. Yo quise cubrirlo de forma sencilla, con hormigón, y bajo su sobrecubierta organizar un pequeño museo de presentación de Medina Azahara. El museo que en nuestros días se ha construido abajo, con gran acopio de medios, yo pretendía ponerlo allí arriba, justo donde tenía que iniciarse la visita, cuya organización también tenía pensada. Se parecía en algo a lo que se ha hecho ahora, o sea, disponer abajo un sitio para aparcar los autobuses, después de haber dejado arriba al visitante, que iba bajando hasta salir por la puerta meridional, donde volvía a coger el autobús.

\section{¿Qué inquietudes tuvo respecto a la urbanística del conjunto?}

Me preocupó mucho la urbanística de Medina Azahara. Traté de organizar las circulaciones para evitar paseos 


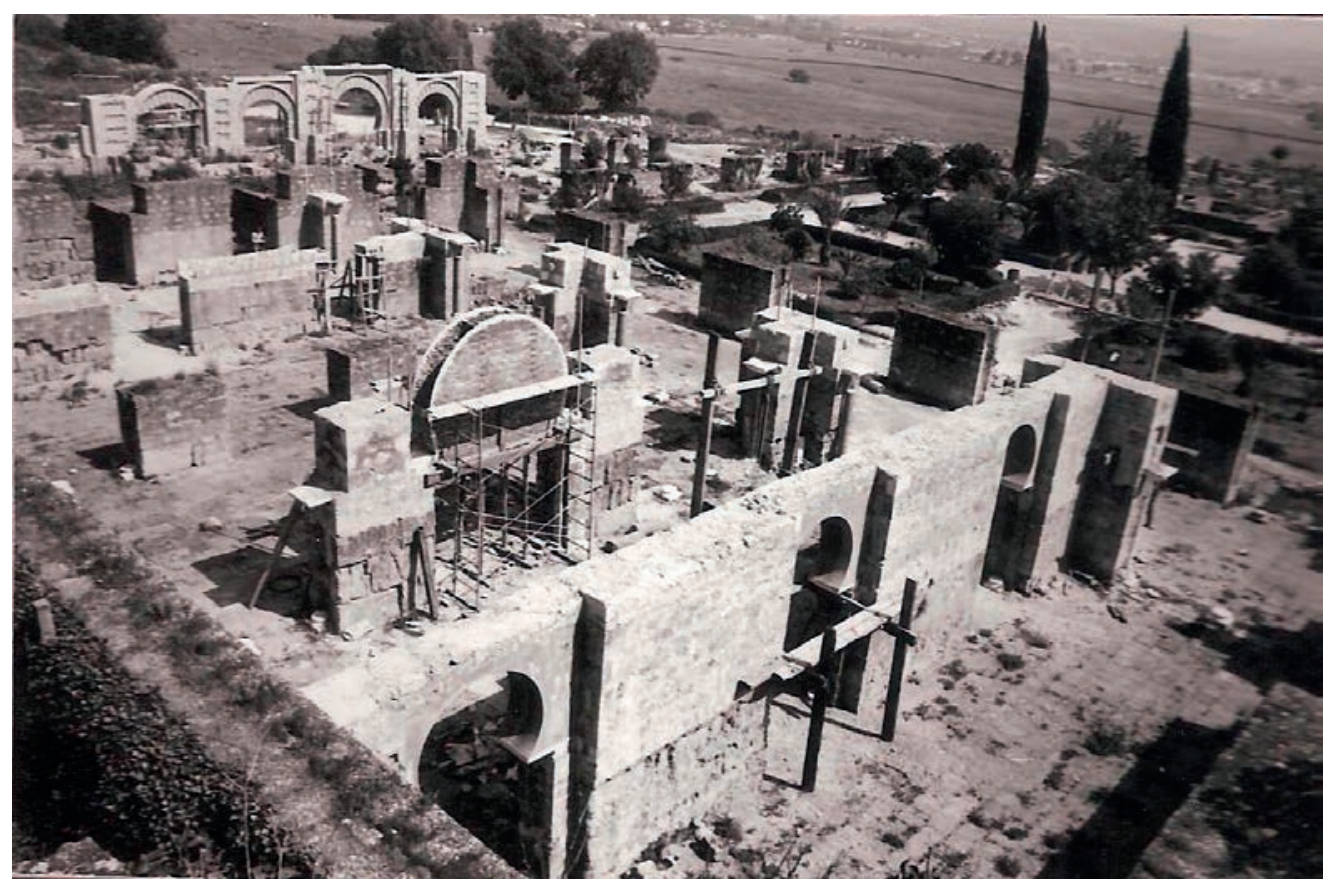

Fig. 12. Intervenciones en la Dar al Yund (ARM).



Fig. 13. Antonio Almagro Gorbea (1992): Conjunto arqueológico de Medina Azahara. 
por pasillos extraños o por un verdadero caos que creaba confusión al visitante. Intenté recuperar las líneas maestras de la urbanística de la ciudad palatina, y en ese sentido acometí mucha de la labor que podía hacerse.

Además quiero recordar algún "canto de sirena" proveniente de países árabes con mucho dinero procedente del petróleo, que parecían dispuestos a financiar reconstrucciones en Medina Azahara. Eso me lo decían, entre otros, el entonces director general de arquitectura Rafael de la Hoz Arderius, que tenía mucho contacto con países árabes y con Córdoba. Estaba muy impresionado con nuestra labor y decía que íbamos a tener que preparar una especie de proyecto de gran alcance, que me daba pánico, por el riesgo que entrañaba para el monumento, a pesar de lo mal que andábamos de medios económicos para todo lo proyectado.

Ante la posibilidad de que hubiese una fuente de financiación y una actividad restauradora importante, pensaba hacer una cosa que creía buena, la reconstrucción de la muralla de cerramiento de Medina Azahara, sacándola de pie, pero no con gran altura, solo para deslindar la totalidad del perímetro y de las murallas interiores entre diversos sectores. Sobre todo me interesaba mucho definir la muralla que servía de muro de contención y de plataforma de los palacios fundamentales, el salón occidental, el oriental o Salón Rico y el salón meridional o pabellón del jardín, centrado entre cuatro albercas.

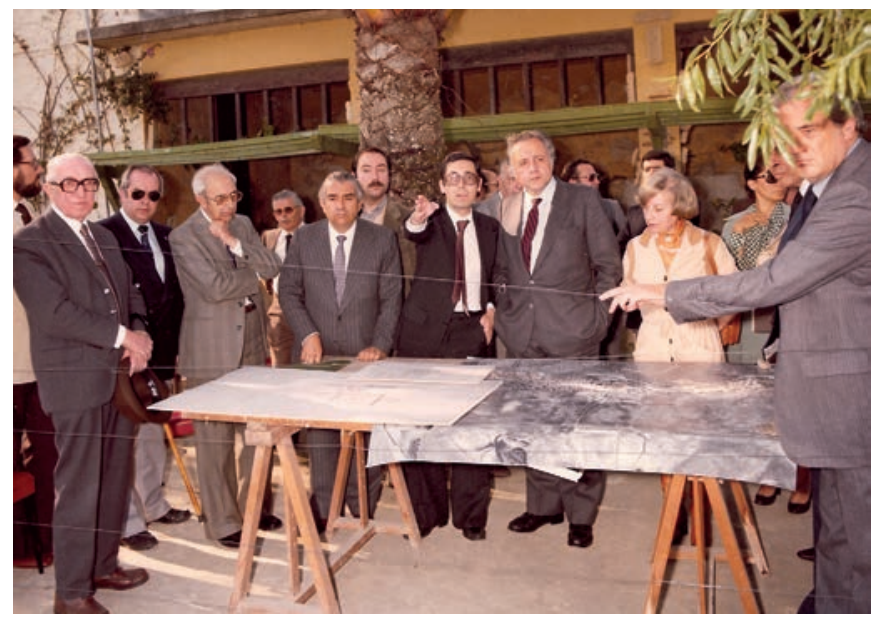

Fig. 14. Rafael Manzano explicando las obras en Medina Azahara, junto al Ministro de Cultura Ricardo de la Cierva y Hoces. Entre otros acompañantes, Juan de Mata Carriazo Arroquia y Ana María Vicent Zaragoza, 1980 (ARM).

\section{¿Qué actuaciones acometió en materia de jardinería?}

Quise excavar el Jardín Alto, lo cual hubiese sido bastante fácil. Entonces ya había estudios palinológicos, que yo apliqué allí, aunque los suelos estaban muy oxidados y los pólenes antiguos excesivamente destruidos. Me ayudó mucho el ingeniero de montes Serafín López Cuervo, y su esposa que era edafóloga. El avance en dichas técnicas hubiese permitido excavar el jardín y haberlo replantado. Para ello necesitaba especies antiguas sin hibridaciones modernas, y conocía dos lugares donde encontrar antiguas simientes, sobre todo de cítricos y de palmeras. Uno era el antiquísimo jardín musulmán de la Cartuja de Santa María de las Cuevas en Sevilla, y otro el jardín del Alcázar de Sevilla. De allí cogí especies y semillas y creé un pequeño vivero en Medina Azahara.
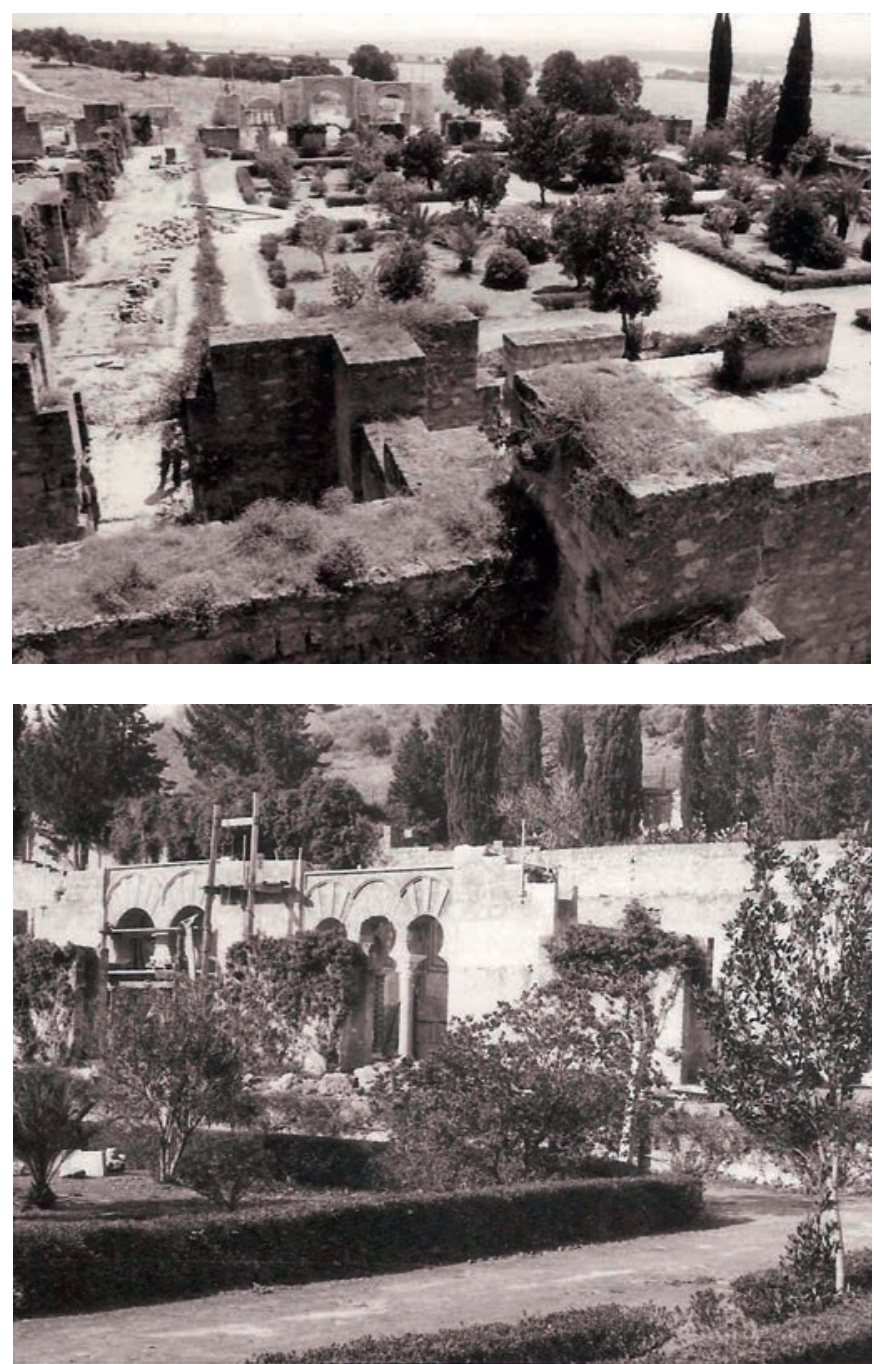

Fig. 15. Jardinería en el conjunto arqueológico (ARM).

En relación con los jardines, otra de las cosas que hice en un primer momento, y que me pareció muy importante, fue la traída de aguas, ejecutada gracias al Ministerio de la 
Vivienda, a través de la Dirección General de Obras Hidráulicas. Me gustaba ver la gran alberca siempre llena de agua; el sol en invierno se reflejaba en ella, e iluminaba los techos del Salón Rico, y aquello era una maravilla.

También traje la luz eléctrica. Hasta entonces todos los morteros se batían a mano y todo tenía un alto coste. La mecanización que aportaba la electricidad y la disponibilidad de agua fue fundamental.

Hice bastante más de lo que la gente pueda pensar por aquel monumento y me preocuparon mucho sus jardines.

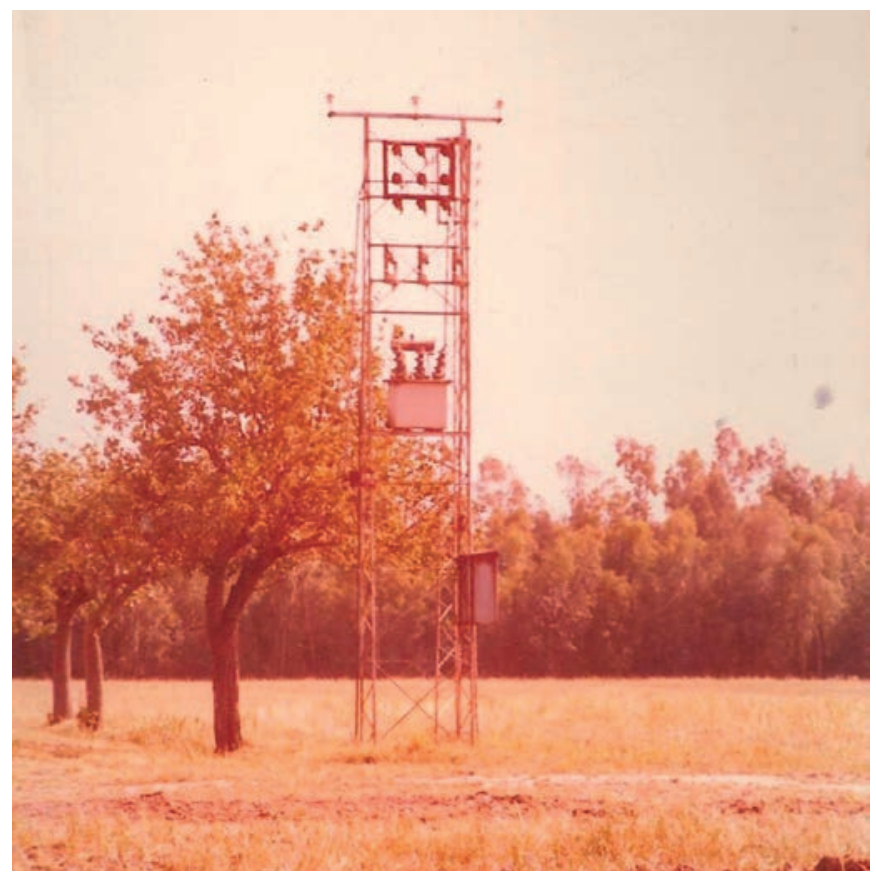

Fig. 16. Llegada del suministro eléctrico a Medina Azahara (ARM).

\section{Además de su gran sentido común, ¿hubo en sus intervenciones arqueológicas otros importantes refe- rentes como guía en su trabajo cotidiano?}

Mi referente por supuesto era la obra de D. Félix Hernández. Recuerdo que él cubría sus intervenciones con persianas de caña, para que no quedasen a la vista del público, y se podía ver muy poco de ellas. Le obsesionaba bastante que D. Rafael Castejón, decano de la facultad de Veterinaria, arqueólogo aficionado y enamorado de Medina Azahara, fotografiase o publicase lo que él había reconstruido. Sin embargo yo dejaba a la vista del público todo lo que se estaba realizando, y eso me permitía corregir errores porque tenía una mejor visión de conjunto, pues siempre intentaba dar una apariencia unitaria y coherente, más allá del estricto valor arqueológico.

\section{¿Con que medios contaba, sobre todo económicos y personales?}

Entonces era muy difícil trabajar casi todo el año sin parones, algo que había sido habitual hasta entonces en Medina Azahara, con los minúsculos recursos económicos que proveía el Ministerio. Hubo algún año que no dieron subvención, y para proseguir la actividad hubo que recurrir a imaginativos procedimientos para obtener dinero y no paralizar las obras.

Recuerdo que los vecinos circundantes pidieron que se les alquilaran los pastos, pero desde Hacienda dijeron que era necesario que saliesen a concurso, y así se hizo. Pero el concurso se publicó, a través de la delegación de Hacienda, fuera de temporada y por supuesto nadie acudió. Sin embargo los pastos había que alquilarlos, porque la hierba crecía demasiado, se secaba en verano y había un serio peligro de incendios.

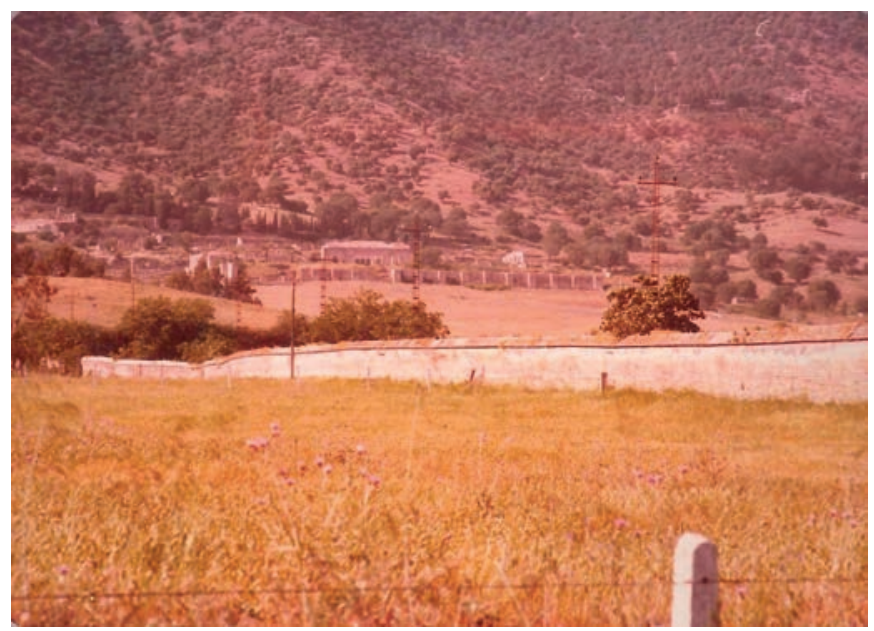

Fig. 17. Pastos en los alrededores del conjunto arqueológico (ARM).

Un asesor fiscal me sugirió la creación de un Patronato de Medina Azahara, que podía aceptar donaciones privadas, abriendo la posibilidad de hacer una especie de concurso para usar los pastos mediante cesión gratuita. El beneficiario hacía luego una donación anual a dicho Patronato y con el dinero de los pastos conseguí que ningún año se interrumpieran las obras. El interventor de Hacienda controlaba los gastos, garantizando que no se malgastaba nada, y yo certificaba los gastos de los empleados. Tenía tres empleados fijos, el encargado de obra, el montador y el escayolista, y cuando había suficiente dinero se contrataba más personal de peonaje.

Esa solución tuvo un inconveniente. Al contar con más continuidad en la financiación, ya no se despedía 
personal anualmente, y los tres o cuatro fijos se fueron convirtiendo en plantilla. Yo no conocía bien el derecho laboral, y cuando salí de Medina Azahara estaban dados de alta a nombre del director, que era yo. Entonces hubo que despedir a dicho personal con su correspondiente indemnización, que era una cantidad considerable. Vino en mi auxilio el Ministerio de Trabajo, que facilitó dinero, en parte gastado en obras y también en indemnizaciones. Pero algún despido lo tuve que pagar yo a expensas de mis honorarios, que eran bastante modestos, $\mathrm{y}$ solo procedentes de los presupuestos oficiales.

\section{¿Había entonces mucho personal de vigilancia?}

No había recursos suficientes para vigilancia. Había perros para vigilar, que por cierto eran muy feroces, pero ello no impedía que pudiesen robar alguna pieza, pues el sistema tenía sus fallos. Y si todo Medina Azahara hubiese estado custodiado en un museo, las piezas habrían perdido la memoria histórica del lugar de donde proceden. Serían muy bellas de ver, pero estarían totalmente descontextualizadas.
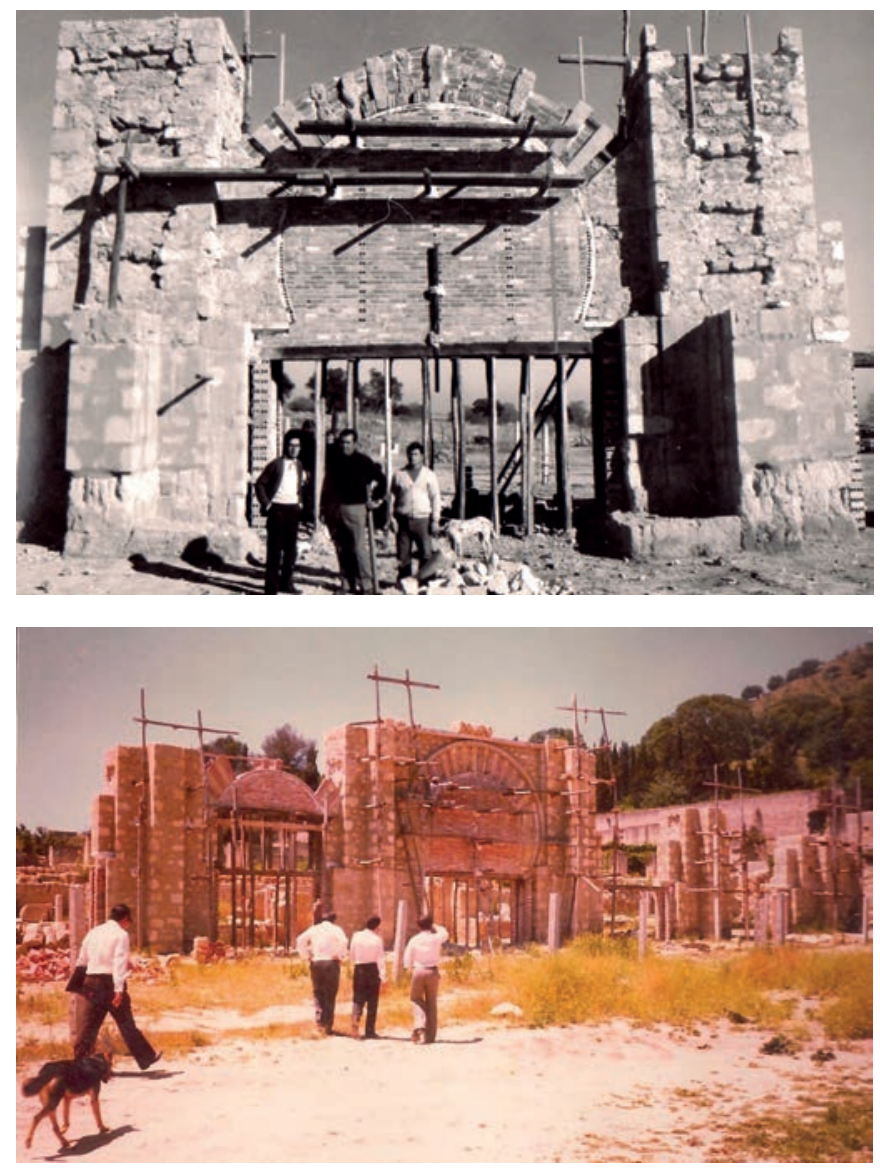

Figs. 18a y 18b Visita de obra [aparecen perros de vigilancia del recinto] (ARM).
¿Cómo se documentaban las actuaciones? ¿Se hacían reportajes fotográficos?

No había dinero para fotografías, ni fotógrafo, ni otros muchos recursos. Las fotografías se hacían con la cámara personal doméstica. Se iban montando piezas y fijándolas directamente en su lugar de origen, fundamentalmente como trabajo de campo. ¿Cuántas personas se hubieran necesitado para catalogar todas las piezas, cada una con su fotografía? Y, ¿qué hubiera hecho yo con las fotografías? Hoy la fotografía es otra cosa muy distinta y ágil, pero entonces sólo se hacían al terminar de montar un paño, y muchas veces las hacía yo. En el archivo de mi propio estudio conservo un álbum con cientos de fotografías de las intervenciones. Pero, según he dicho, apenas había personal, ni siquiera un espacio de oficina adecuado. Poco a poco yo fui mejorando lo que pude.



Fig. 19. Álbum fotográfico sobre Medina Azahara (ARM).

Aunque hubiese una importante escasez de medios, no debe olvidarse la importancia de seguir criterios adecuados en cada caso. Recuerdo, por ejemplo, la puerta del palacio de Yaafar, que montó D. Félix, que ha sido recientemente desmontada y se ha vuelto a reintegrar, aunque creo que estaba mejor antes, pues no sólo se trata de documentar arqueológicamente y diferenciar la nueva intervención de lo antiguo, el conjunto debe tener cierta belleza. Yo creo que la arquitectura debe tener algo de gracia o atractivo, y a veces debe actuarse más como arquitecto que como arqueólogo.

La escasez de medios no impidió el montaje "in situ" de determinados hitos arquitectónicos, como la portada monumental del palacio de Yaafar, que restituyó con muy buen criterio Don Félix Hernández, y que ha perdido en calidad arquitectónica al ser recientemente desmontada y reconstruida. Debe considerarse que una de las grandes enseñanzas respecto al lenguaje arquitectónico del califato es el uso sistemático de la alternancia 
de los fustes de columnas de color rosa de Cabra, con los grises oscuros de la sierra de Córdoba, en correspondencia con capiteles corintios y compuestos, una cuestión que se ha obviado en el montaje actual.

\section{¿Qué importancia tuvo su vertiente profesional como historiador de la arquitectura?}

Por supuesto la historia es un conocimiento imprescindible. Yo conocía genéricamente el arte hispanomusulmán, pero además, allí estaba aprendiendo la evolución piedra a piedra del arte califal. En la Mezquita, a través de mis maestros y de los textos de Alhakén, encontramos los mismos autores que en Medina Azahara, ya muy experimentados, y algunos temas de Medina Azahara fueron perfeccionados en la Mezquita, como por ejemplo los cuatro tableros del mihrab, que son la perfección del arte de todos los zócalos de Medina Azahara.

Recuerdo que entonces apenas tenía tiempo libre y no tuve ocasión de viajar a Siria para rastrear los orígenes del arte omeya. Pero en una importante exposición que tuvo lugar a principios de este siglo, se trajeron piezas omeyas con arcos de herradura o múltiples arquillos entrelazados, que para mí fueron una verdadera revelación. Todos creíamos que los arcos entrecruzados de la Mezquita lo eran para resistir mejor el empuje de los lucernarios, pero entonces pude comprobar que existieron ya como tema decorativo en Oriente.

En todo caso, el contacto cotidiano con el monumento me dio a conocer en profundidad el lenguaje arquitectónico de la arquitectura del califato tanto en su vertiente civil y domestica como en la religiosa, porque muchas de las formulas y trazas compositivas de Medina Azahara, están luego aplicadas en la ampliación de Alhakén II de la Mezquita, a veces introduciendo novedades, aunque es evidente que en ella trabajaron muchos artistas del mármol y decoradores de la gran ciudad palatina que infundieron un carácter religioso a formas que quedaron para siempre adscritas a la arquitectura civil. Por ejemplo, la alteración en el colorido de los fustes, ya intuida en la Mezquita de Abderramán II y llevada a la perfección en Medina Azahara se aplica también en la nueva ampliación de la Mezquita, pero suprimiendo en ésta el uso de basas decoradas, colocando el fuste directamente sobre el pavimento -que surge como un fuste vegetal- siguiendo la tradición de la primera Mezquita en que las basas y las propias columnas iban enterradas y servían exclusivamente como placas de cimentación. También los capiteles se utilizaron alternando corintios y compuestos pero en "sólido capaz", como se preparaban para su trepanado, entonando mejor y con mayor severidad con los bastos capiteles visigóticos de las dos primeras Mezquitas...

\section{¿Qué singularidades arqueológicas destacaría de Medina Azahara?}

Medina Azahara es una ciudad palatina muy arquetípica, muy única como conjunto arqueológico, muy de su época, totalmente destruida pero milagrosamente intacta en sus elementos decorativos, en su composición y su urbanismo.

Es increíble que se haya podido realizar una anastilosis, que por supuesto no es la misma anastilosis del Partenón o de otros monumentos. Se han podido reintegrar espacios fundamentales, y conocerlos objetivamente, debido a la singularidad de sus restos arqueológicos. Sus muros fueron expoliados y sus materiales reutilizados, pero no la decoración, que en parte cayó en el incendio que allí hubo, o bien se arrancó, pero se dejó en el sitio para extraer la piedra que le servía de base. Desaparecieron los fustes de las columnas pero muchos capiteles permanecieron allí, junto a otros fustes rotos al intentar extraerlos. Las parroquias fernandinas y muchos palacios de Córdoba se construyeron con piedra de Medina Azahara y muchos contratos de obra de entonces decían: "la piedra será de la dehesa de Córdoba la Vieja".

El Salón Rico conservó relativamente bien sus arquerías porque éstas se derribaron tirando de sus columnas, incluso aplastando a alguna persona allí presente. Recuerdo que D. Félix comentaba que no dio cuenta al juzgado sobre los restos óseos encontrados en este lugar.

\section{¿Qué elementos arquitectónicos subrayaría como más relevantes del conjunto?}

En Medina Azahara la decoración es más importante que los espacios arquitectónicos, que no son especialmente novedosos. Éstos se configuraban en muchos casos como espacios basilicales, que no derivan de las basílicas clásicas sino de mezquitas con naves paralelas de igual altura.

Hubo otro modelo de salón que me hubiese gustado excavar, pues intuía donde pudo estar emplazada la $q u b$ $b a$ de Medina Azahara, que sería la primera qubba-salón abovedada construida en la España musulmana. Luego se construyeron las cuatro de Alhakén II, de nervios de tipo armenio, en la Mezquita. Pero ésta debió de ser ligera, como la de la Mezquita de la Roca de Jerusalén, con cubierta leñosa. Estas bóvedas marcaron para siempre la imagen de palacios, mezquitas e iglesias posteriores que usaron qubbas de tradición islámica. 
En edificios civiles era más frecuente el uso de la cúpula esférica leñosa o poligonal ochavada que la nervada, por la mayor fragilidad y por la ausencia de estribos suficientes para recibir los empujes en una nervada. No obstante existió en algún palacio almohade, por ejemplo, la denominada $\mathrm{n}^{\circ} 6$ en la Casa Toro-Buiza, comentada en mi texto "Casas y palacios en la Sevilla almohade. Sus antecedentes hispánicos" [en Casas y palacios de Al-Andalus. Siglos XII y XIII, 1995, p. 333]. Por estas razones y por paralelismo con el modelo gótico, la bóveda nervada se aplicó más universalmente a los edificios religiosos, tanto islámicos como cristianos, como por ejemplo ocurrió en la capilla de los Talavera en el claustro de la catedral de Salamanca. Las qubbas en edificios religiosos nunca se hicieron de madera, sino nervadas. En todas las catedrales, capillas o capillas funerarias la qubba es pétrea y nervada, mientras que las qubbas civiles del Alcázar de Sevilla o del Salón de Embajadores de la Alhambra, partieron del modelo de Medina Azahara, que tendría una copia temprana en Sevilla, pues el rey Almutamid estuvo en Córdoba y conocía Medina Azahara.

\section{¿Qué otras lecciones de Medina Azahara podría destacar?}

En Medina Azahara se plantearon cuestiones del mayor interés referentes al arte islámico, y a los inicios del lenguaje arquitectónico hispanomusulmán, que luego evolucionó muchísimo. Allí estaban los fundamentos o esencias de la arquitectura doméstica y palatina del Islam andalusí, que antes debió ser muy modesta, según ocurriría en el Alcázar emiral de Córdoba, pues, según lo excavado, se vislumbra que era un edificio modestísimo. La arquitectura que nació en la Mezquita, evolucionó bajo la dirección de un califa arquitecto, Alhakén II, que fue el gran coautor en la construcción de Medina Azahara, donde como joven príncipe dedicó sus ocios a construir la gran ciudad palatina fundada por su padre Abderramán III.

Parece que la labor de este príncipe-arquitecto resultaría crucial, al igual que ocurrió en El Escorial, o en el antiguo templo de Salomón. Ordenaría el conjunto y sería el teórico e impulsor que guió a los artesanos que lo construyeron, cuyas firmas aparecen en capiteles, decoraciones o columnas, algunos de ellos cristianos.

Otros artistas vendrían para hacer riquísimas piezas de marfil, como ajuar de estos palacios, y contribuyeron a la evolución de la decoración y a la difusión de novedades. Hubo un verdadero diálogo de temas decorativos entre dichas piezas de marfil y la decoración arquitectónica pétrea.
Muchos de sus temas, traídos de oriente, evolucionaron y se convirtieron en arte propio. Surgió una impresionante variedad de modelos andalusíes que luego pasaron al norte de África, de la mano de artistas cordobeses en tiempos del califato almorávide de Yusuf ben Taxfin, que fueron enviados por su hijo Alí, el gobernador de Córdoba, a trabajar en mezquitas del norte de África. Allí se implantó un arte que evolucionó dentro de la austeridad almohade, y más adelante de allí saldría el arte nazarí. Esta evolución del lenguaje artístico vino concatenada desde las primeras Mezquitas de Abderramán I y Abderramán II, de Medina Azahara y la Mezquita de Alhakén, hasta tiempos de Almanzor.

\section{¿Cree que el conjunto de Medina Azahara es poco valorado por los arquitectos actuales, $\mathrm{o}$ que sus valo- res arquitectónicos son poco comprendidos?}

En la Alhambra de Granada pueden vislumbrarse episodios de una arquitectura más moderna, consecuencia final de un largo proceso evolutivo del lenguaje arquitectónico que se inició en la Mezquita de Córdoba y en Medina Azahara, y que afectó a toda la arquitectura hispanomusulmana. En el Manifiesto de la Alhambra, ésta se presenta en pro de una arquitectura contemporánea, pero de Medina Azahara puede extraerse bastante menos en pro de una arquitectura actual. Por ello quizás no interese tanto a los arquitectos de nuestros días, como tampoco creo que interese demasiado una catedral gótica, que a menudo se contempla como simple curiosidad, pues apenas puede extrapolarse modernidad de ella. La arquitectura de Medina Azahara, profundamente decorativa y atectónica, dista del lenguaje de la modernidad arquitectónica.

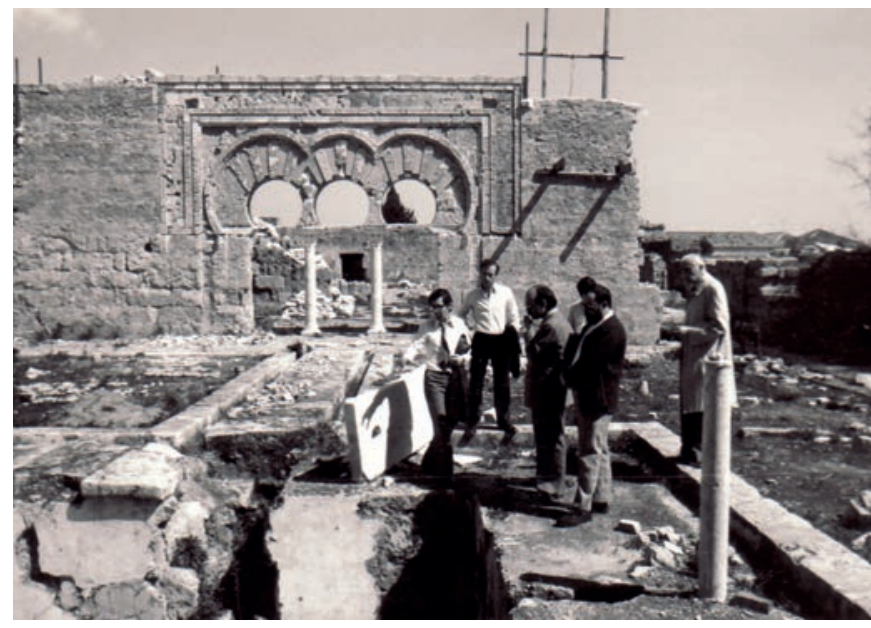

Fig. 20. Rafael Manzano con arqueólogos y arquitectos en la Casa de la Alberquilla (entre ellos, Ramón Corzo Sánchez y Alfonso Jiménez Martín) (ARM). 
Quizás interese más a los arquitectos de nuestros días como paisaje para dar un paseo. Si viésemos su conjunto con su jardinería quizás resultase más atractivo para los arquitectos actuales. Pero la jardinería apenas se ha exhumado y estudiado, salvo en el patio de la Alberquilla.

\section{¿Cree que sus intervenciones en Medina Azahara son conocidas y valoradas?}

Los cordobeses estaban muy contentos con mis intervenciones porque veían como crecía Medina Azahara, en especial el Salón Rico, que había sido un sitio repleto de piedras en el suelo, que fueron colocadas en su sitio. Quizás gustaron menos a algunos que trabajaron allí después que yo, pero que ahora en el fondo posiblemente intentan seguir criterios parecidos a los míos.

La citada intervención ha sido aplaudida en el extranjero y aparece en muchas publicaciones de arte hispanomusulmán, como por ejemplo el libro de Marianne Barrucan y Achim Bednorz, "Arquitectura Islámica en Andalucía", que publicó Taschen con gran difusión internacional. En todas las publicaciones de arte califal en el mundo y de arte califal en España aparecen fotos maravillosas del Salón Rico, como algo plenamente satisfactorio, que hay que proseguir y acabar, pues

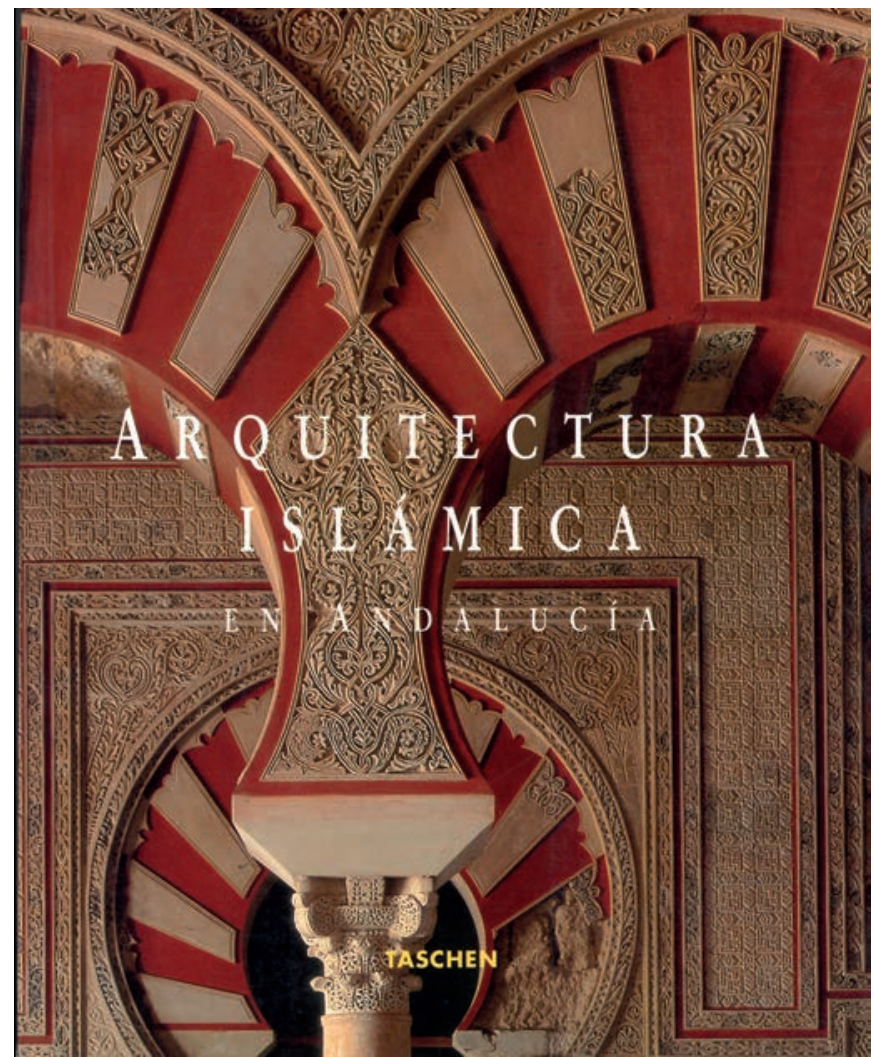

Fig. 22. Portada del libro Arquitectura Islámica en Andalucía.

supone un avance en el conocimiento de la decoración y de las estructuras del califato omeya.

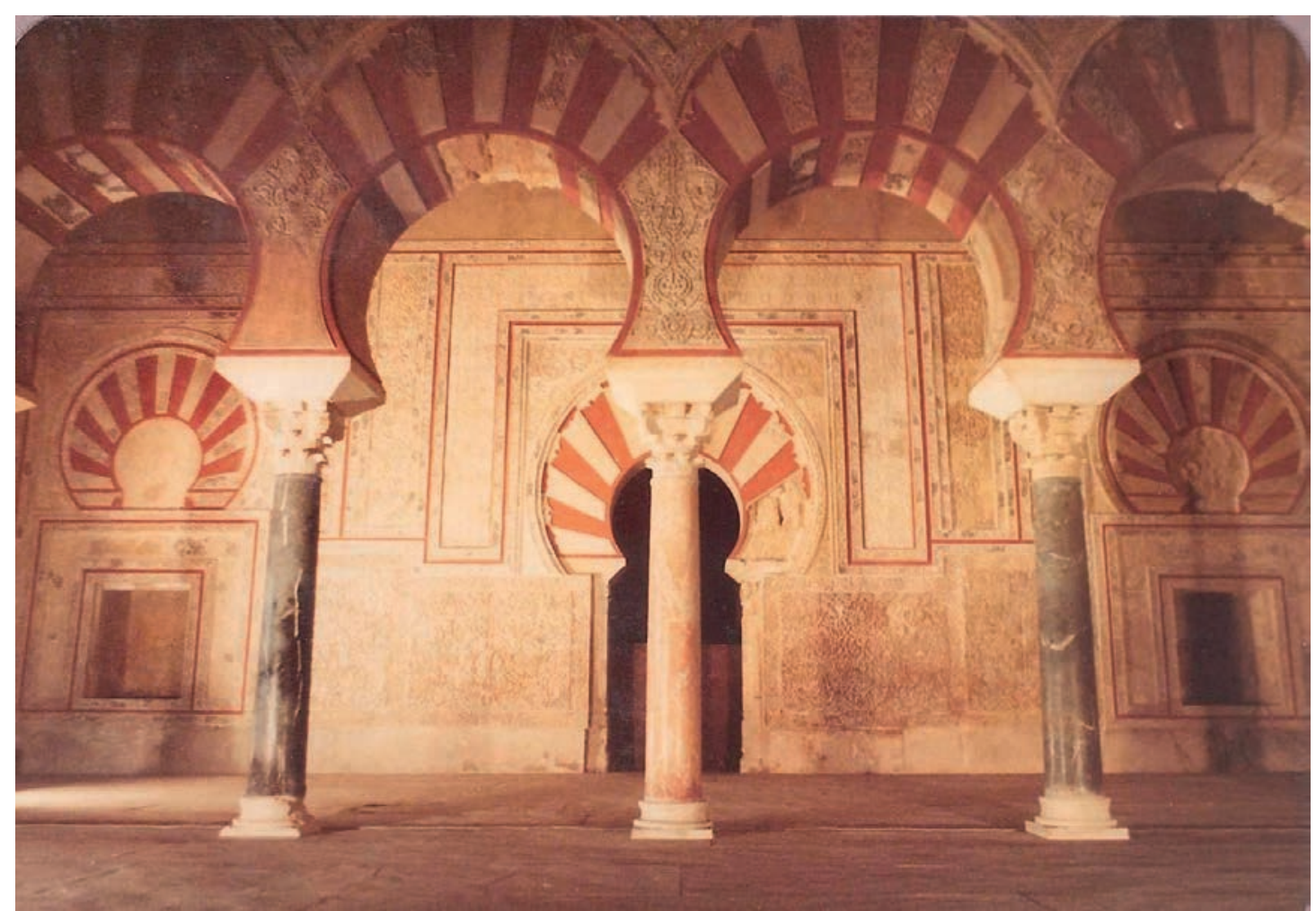

Fig. 21. Vista del Salón Rico en 1981 (ARM). 


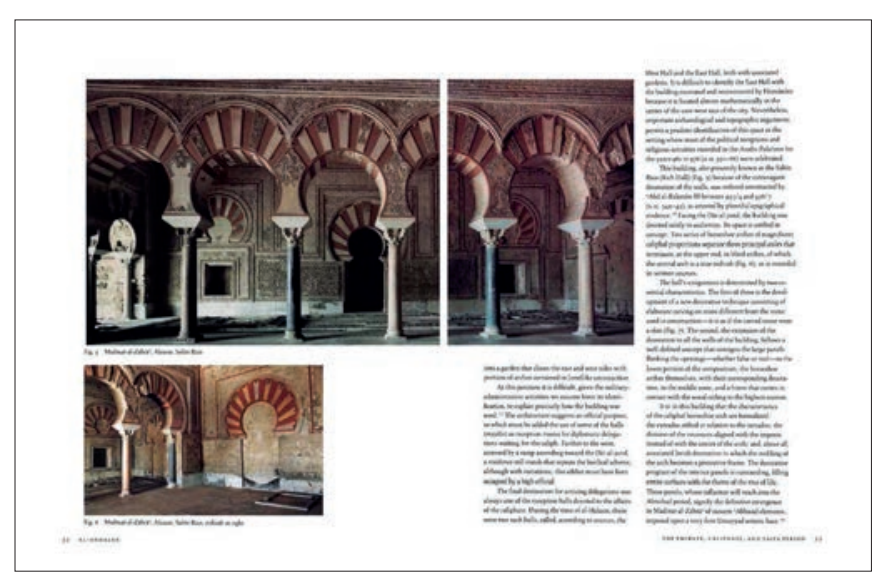

Fig. 23. Doble página con fotos del Salón Rico en el catálogo "Al Andalus. The Ar of Islamic Spain" editado por el Metropolitan Museum de Nueva York.

La Medina Azahara que hoy vemos sigue pareciéndose bastante a la que yo dejé, incluso algunos elementos colocados provisionalmente siguen allí desde hace cuarenta años. Precisamente en estos días he oído algo de que la Unesco quiere declarar Patrimonio de la Humanidad a este conjunto arqueológico.

Ahora se están intentando continuar y completar mis intervenciones de la mano de la fundación World Monuments Fund, interesada por Medina Azahara. Fui el arquitecto de los padres de sus principales patronos actuales en un palacio en Córdoba, y en una masía catalana, y ellos han querido que yo estuviese en el equipo de trabajo. Gracias a dicha fundación se ha trabajado durante tres años, aunque ahora se ha parado, al parecer por falta de recursos económicos, algo que no me explico, pues las cifras disponibles las creíamos más que suficientes...

\section{¿Qué consejo daría a futuros conservadores de Medina Azahara como fruto de su experiencia?}

Quiero subrayar la importancia del diálogo y la necesaria complementariedad entre arquitectos y arqueólogos, pues toda reconstrucción debe hacerse siempre con la mayor fundamentación arqueológica posible y hasta el límite adecuado en cada caso.

No todos los espacios de Medina Azahara se pueden llegar a cubrir como el Salón Rico, aunque la experiencia ha demostrado que dicha cubierta ha permitido su salvación. Una ciudad palatina tan compleja necesita reductos de protección en su visita turística. Según he comentado, me hubiese parecido interesante cubrir la Dar al Yund, y haber hecho allí un pequeño museo de muestras de temas geométricos, florales, de ataurique... de todos los motivos decorativos, si bien es verdad que ahora pueden verse en el nuevo edificio construido, que está muy bien, al estar rehundido en el terreno, ser discreto de traza y además no altera el paisaje del conjunto monumental.

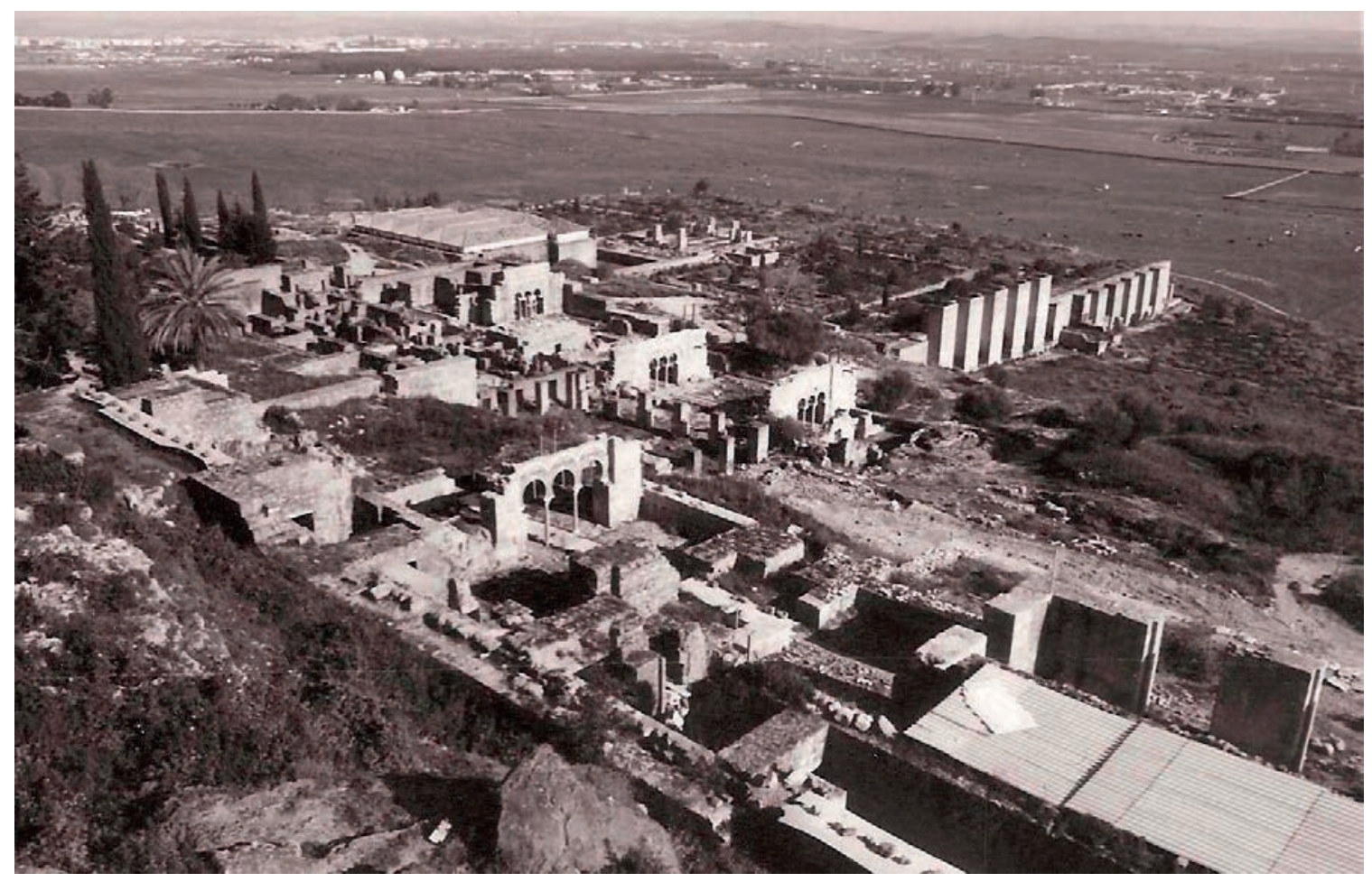

Fig. 24. Vista panorámica de Medina Azahara (ARM). 


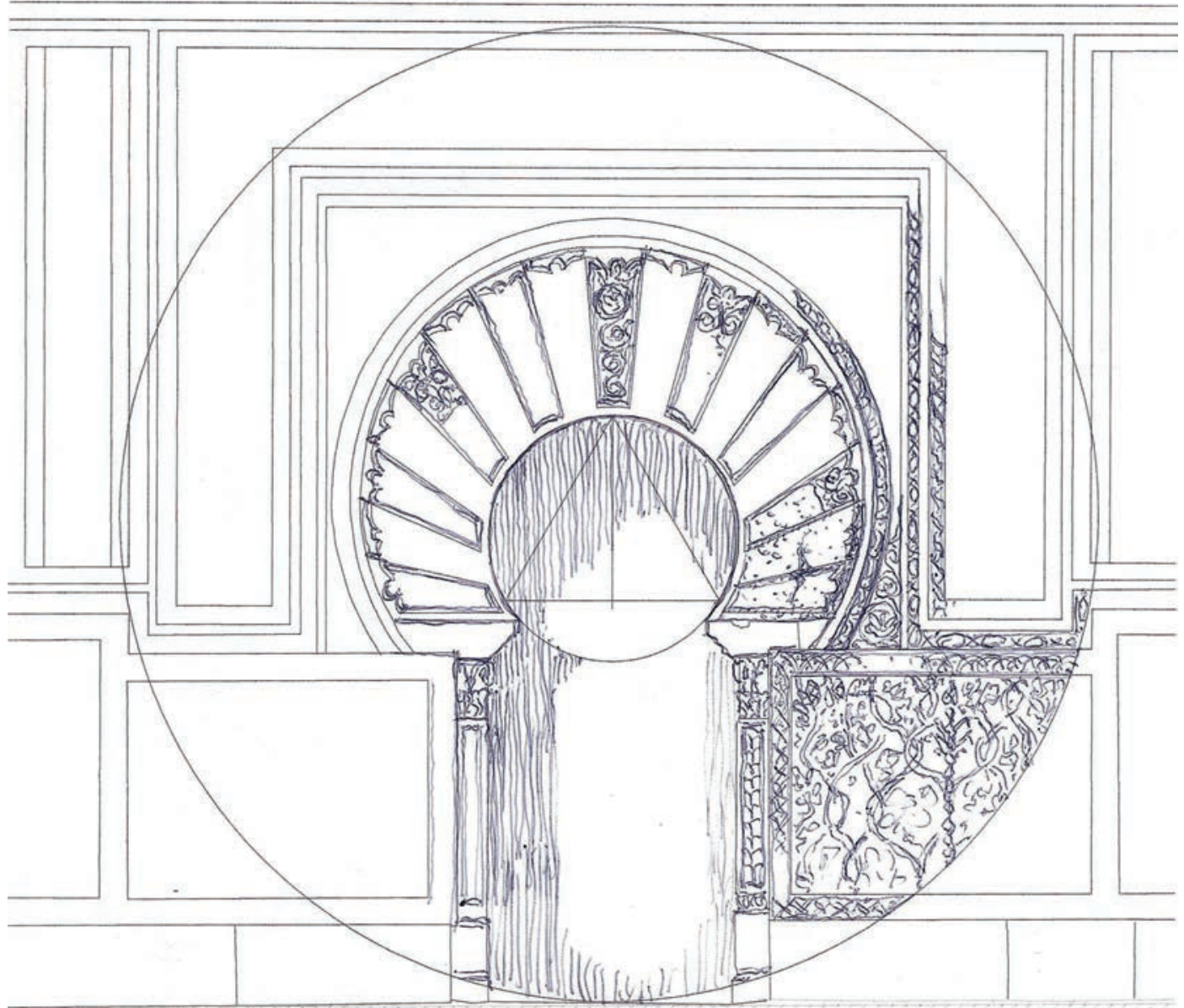

Fig. 25. Diseño de medalla para el ganador del premio de Arquitectura Clásica y Restauración de Monumentos Rafael Manzano Martos (Dibujo de Rafael Manzano). 